\title{
8-Hydroxydihydrosanguinarine (8-HDS), a pyridone containing analogue of sanguinarine, can be a potential inhibitor of $S$ protein and $M$ protease of SARS CoV2: Insights from computational studies
}

\section{Atala Bihari Jena}

Centre Of Excellence In Integrated Omics and Computational Biology, Utkal University, Bhubaneswar 751004, Odisha. https://orcid.org/0000-0002-1690-7913

\section{Namrata Kanungo}

Post Graduate Department of Biotechnology, Utkal University, Bhubaneswar 751004, Odisha. https://orcid.org/0000-0001-9891-8589

\section{Gagan Bihari Nityananda Chainy}

Post Graduate Department of Biotechnology, Utkal University, Bhubaneswar 751004, Odisha. https://orcid.org/0000-0002-6418-0480

\section{Vinod Devaraji}

Computational Drug Design Lab, School of Bio Sciences and Technology, Vellore Institute of Technology, Vellore-632014, Tamil Nadu, India. https://orcid.org/0000-0002-9355-3995

Jagneshwar Dandapat ( $\nabla$ jdandapat.nou@gmail.com )

Post Graduate Department of Biotechnology, Utkal University, Bhubaneswar 751004, Odisha. https://orcid.org/0000-0003-0928-1585

\section{Research Article}

Keywords: Sanguinarine, 8-Hydroxydihydrosanguinarine, S Protein, M Protease, SARS CoV 2, Molecular Dynamics

Posted Date: January 27th, 2021

DOI: https://doi.org/10.21203/rs.3.rs-153786/v1

License: (c) (1) This work is licensed under a Creative Commons Attribution 4.0 International License. Read Full License 


\title{
8-Hydroxydihydrosanguinarine (8-HDS), a pyridone containing analogue of sanguinarine, can be a potential inhibitor of $S$ protein and M protease of SARS CoV2: Insights from computational studies
}

\author{
Atala B. Jena ${ }^{a^{* * *}}$, Namrata Kanungo ${ }^{b^{* * *}}$, G. B. N. Chainy ${ }^{b}$, Vinod Devaraji ${ }^{c}$, Jagneshwar \\ Dandapat $^{\mathrm{a}, \mathrm{b} *}$
}

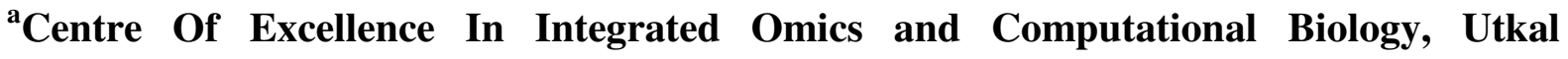
University, Bhubaneswar 751004, Odisha.

${ }^{b}$ Post Graduate Department of Biotechnology, Utkal University, Bhubaneswar 751004, Odisha.

cComputational Drug Design Lab, School of Bio Sciences and Technology, Vellore Institute of Technology, Vellore-632014, Tamil Nadu, India.

*Corresponding Author: jdandapat.nou@gmail.com

(Prof. J. Dandapat)

**Joint first author (Contributed equally)

\section{$\underline{\text { ABSTRACT }}$}

The unprecedented global pandemic of COVID-19 has created a daunting scenario urging an immediate generation of therapeutic strategy. Interventions to curb the spread of viral infection primarily include setting targets against the virus. Here in this study we target $S$ protein to obstruct the viral attachment and entry and also the $M$ pro to prevent the viral replication. For this purpose, the interaction of $\mathrm{S}$ protein and $\mathrm{M}$ pro with phytocompounds, sanguinarine and eugenol, and their derivatives were studied using computational tools. It is evident from the docking studies that 8-Hydroxydihydrosanguinarine, a derivative of sanguinarine, exhibits maximum binding affinity with both the targets. The binding energies of the ligand with $\mathrm{S}$ protein and $\mathrm{M}$ pro scored to be $\Delta \mathrm{Gb}-9.4 \mathrm{Kcal} / \mathrm{mol}$ and $\Delta \mathrm{Gb}-10.3$ $\mathrm{Kcal} / \mathrm{mol}$ respectively. MD simulation studies depict that the phytocompound could 
effectively cause structural perturbations in the targets which would affect their functions. 8Hydroxydihydrosanguinarine distorts the $\alpha$-helix in the secondary structure of $\mathrm{M}$ pro and RBD site of $\mathrm{S}$ protein. Protein-protein interaction study in presence of 8hydroxydihydrosanguinarine (8-HDS) also corroborate the above findings which indicate that this polyphenol interfere in the coupling of $\mathrm{S}$ Protein and ACE2. The alterations in protonation of $\mathrm{M}$ pro suggest that the protein structure undergoes significant structural changes at neutral pH. ADME (Physicochemical, Lipophilicity, Water Solubility, Pharmacokinetics, Drug-likeness) property of 8- hydroxydihydrosanguinarine suggests that this could be a potential drug. This makes the phyto-alkaloid a possible therapeutic molecule for anti COVID-19 drug design.

Key words: Sanguinarine, 8-Hydroxydihydrosanguinarine, S Protein, M Protease, SARS CoV 2, Molecular Dynamics. 


\section{INTRODUCTION}

The ominous COVID-19 has gripped the globe with panic and distress. The coronavirus, also known as SARS-CoV2 because of around $79.5 \%$ genomic identity with the RNA of SARS $\mathrm{CoV}$ [1], belongs to genus betacoronavirus [2-4]. Due to its high rate of transmission and unavailability of specific therapy, it was proclaimed as a pandemic by WHO.

SARS-CoV2, the enveloped, positive sense, single stranded RNA virus, causes respiratory infections in humans [5].The single stranded genomic RNA, $30 \mathrm{~kb}$ in length [6], comprises atleast 6 open reading frames (ORFs) along with 5' cap structure and 3' poly A tail [7]. The first ORF occupying about two-third of the genome length encodes two translational products, polyproteins - ppla and pplab [8] which mediates viral replication and transcription. The viral expression is coordinated by a highly complex proteolytic processing cascade [9]. The M pro, main protease (also known as 3 CL-pro) plays a pivotal role in processing these polyproteins into 16 mature non- structural proteins (nsp) [8]. The nsps are employed for the production of sub genomic RNAs which are required for synthesis of the structural proteins i.e. envelope (E), spike (S), membrane (M), and nucleocapsid $(\mathrm{N})$ proteins and other accessory proteins.

Various X-Ray crystallographic studies $[7,10]$ depict that $\mathrm{M}$ pro comprising protomers a and b consists of 306 Amino acid residues. Each protomer consists of three domains, domain-I (8 -99 aa residues), domain-II (100 -183 aa residues) and domain-III (200 -306 aa residues). A connecting loop, between domain II and III, spans from 184 to 199 residues. The N-terminal or $\mathrm{N}$ finger (1- 7 residues) is responsible for the proteolytic activity [11,12] whereas, the $\mathrm{C}$ terminal domain III of $\mathrm{M}$ pro plays a major role in the dimerization of protomers a and $\mathrm{b}$ [13].

The establishment of SARS-CoV in the host cell involves proteolytic processing events mediated through $\mathrm{M}$ pro which direct gene expression and replication [14]. There are about 11 cleavage sites of $\mathrm{M}$ pro on the larger polyprotein pp1ab with Leu-Gln $\downarrow$ Ser, Ala, Gly as recognition sequence. Thus inhibiting this protease activity would block viral replication [15]. Incorporation of protease inhibitors such as lopinavir/ritonavir into $\mathrm{CoV}$ infected patients has responded with healthier consequences [16]. Cure to such infections might be more improved by administration of non-covalent protease inhibitors. Most of the anti-SARS approved drugs were intended for certain other viral strains. Recently, a few clinical development programs have effectively accomplished with a CoV protease specific inhibitor [17]. While clinical trials are sprinting for resolving the broad range efficiency scale of 
various molecules in infected patients, the main protease ( $\mathrm{M}$ pro) seems to be a promising target in drug design $[18,19]$.

The entry of SARS-CoV-2 into host cells is mediated through the binding of glycoproteinous spike protein of the virus, the $\mathrm{S}$ protein and host cell membrane receptor, i.e. Angiotensin Converting Enzyme 2 (ACE2) [20] (Fig. S1). Lu et al., 2020 have suggested that receptor binding domain (RBD) of S-glycoprotein of SARS-CoV2 being similar to that of SARS$\mathrm{CoV}$, targets Angiotensin Converting Enzyme 2 (ACE2), a monomeric membrane bound receptor on human cells [21]. Hence, it is presumed that blocking the RBD site of the spike protein would prevent viral attachment to the ACE2 receptor and entry into the host cells, thus specifying it as a target to prevent the viral infection [20,22]. Though a few recent and related studies have suggested various natural products for the development/repurposing of anti SARS-CoV2 drug targeting Spike glycoprotein, Membrane glycoprotein and Main protease $[20,23,24]$, to the best of our knowledge none has investigated the potentiality of sanguinarine or eugenol for this purpose.

This study, therefore, takes interest in inspecting the competence of two phytocompounds, sanguinarine and eugenol and their derivatives, in preventing viral infection/replication by inhibiting $\mathrm{M}$ pro and blocking $\mathrm{S}$ protein through in silico approaches. Virtual screening of sanguinarine and eugenol derivatives was conducted on the basis of molecular interaction, out of them 8-hydroxydihydrosanguinarine (8-HDS) showed the highest binding affinity. 8HDS, a derivative of sanguinarine, obtained from Chelidonium majus $L$ and is a benzo [c] phenanthridine type alkaloid [25]. Sanguinarine, is known for its wide range of biological activities such as regulation of nuclear factor NF- $\kappa \mathrm{B}$, apoptosis and disintegration of microtubules [26]. Pyridone containing analogues indeed have been proven to be potent in preventing viral replication by inhibiting certain essential viral enzymes [27]. Also tests have been conducted for pyridone derivatives for anti-hepatitis B virus (HBV) activity and cytotoxicity in vitro [28]. Therefore, 8-HDS containing pyridone ring might prove to be effective in averting SARS CoV 2 infection [15] (Fig. S2).

Needless to mention that computational study minimizes biological waste, research time span and is cost-effective. In this context we have employed various computational approaches (Molecular docking and simulation) for designing of natural compound based therapeutic intervention against COVID-19. Findings of this computational study indicate the potentiality of 8-HDS as an effective and promising therapeutic agent for SARS-CoV 2. 


\section{MATERIALS AND METHODS}

\subsection{Sequence analysis}

Using PDB database, the cryo EM structure of COVID-19 S protein (PDB ID - 6vsb) and XRay diffraction structure of COVID-19 M pro (PDB ID-6y84) having resolution $3.46 \AA$ and $1.39 \AA$ respectively have been obtained for computational study. For analysing multiple sequence alignment the FASTA sequences of M protein of 2019-nCoV, MERS-CoV, HCoVNL63, SARS-CoV were also derived. FASTA sequence of M pro of above PDB structure was taken for the analysis of its physicochemical property and secondary structure prediction in ExPASy ProtParam and SOPMA tools, respectively.

\subsection{S-protein- ACE2 interaction in presence of 8-HDS}

A computerised rigid body docking tool, clusPro2.0 was used for S-protein- ACE2 protein docking analysis in presence or absence of 8-HDS. This tool helps in screening docked conformations with respect to their clustering properties taking into consideration different protein parameters. The selection of the filtered conformations was based on the assessment of empirical free energy. Both lowest de-solvation and electrostatic energies were taken into account for the evaluation of free energy. ClusPro is accessible at https://cluspro.bu.edu/publications.php. Piper, being a FFT-based rigid docking tool, serves the ClusPro clustering program for detecting native site by providing 1000 low energy outcomes [29]. The native site is assumed to possess a wide range of free-energies to draw greater number of results. Initially the sample was taken for about $10^{9}$ positions of the ligand with respect to the receptor. Out of these, only the top $10^{3}$ positions were selected among all relative ligand positions in correspondence to the receptor.

\subsection{Molecular docking analysis between $M$ pro and $S$ protein with sanguinarine and eugenol}

The binding affinities of $\mathrm{M}$ pro and $\mathrm{S}$ protein with different derivatives of sanguinarine and eugenol were evaluated through molecular docking program AutoDock Tools 1.5.6. The canonical SMILES ids of sanguinarine and eugenol along with their derivatives were acquired from PubChem database (https://pubchem.ncbi.nlm.nih.gov/). CHIMERA 1.11.2 [30] programme was used for the conversion of 3D structures. Binding affinity of $M$ pro and $S$ protein with derivatives of sanguinarine and eugenol was estimated using AutoDock Vina1.1.2 [31]. Various parameters such as binding affinity, receptors interacting atom, 
receptor pocket atom, receptor ligand interaction site, atomic contact energy (ACE) and side amino acid residues were studied to recognise the binding site of $\mathrm{M}$ pro. Virtual screening of sanguinarine and eugenol derivatives was conducted on the basis of molecular interaction. Pictorial depiction of docking results were analysed by Discovery Studio 2017 R2 Client [32].

\subsection{Molecular simulation}

The ligand 8-HDS was extracted in chemically unstandardized 2D structures from PubChem database (https://pubchem.ncbi.nlm.nih.gov/). LigPrep [33] was used to standardise the ligand files, lower energy and extrapolated 3D structures which were virtually screened by Glide [34]. The 'M protein - 8-HDS' and 'S protein- 8-HDS' complex was formed using Grid-based Ligand Docking with Energetics (GLIDE) module of Schrodinger software. Molecular dynamics simulations were determined using Desmond [35] software. Root Mean Square Deviations (RMSD) and atomic fluctuation were studied through Root Mean Square Fluctuation (RMSF) studies. Different simulation boxes and tools such as cubic, orthorhombic, truncated octahedron and rhombic dodecahedron were taken up for precisely directing solvent simulations with periodic marginal conditions. An 8- staged stabilization run was conducted prior to $100 \mathrm{~ns}$ production run. Beginning primarily with task, then followed by simulations with NVT at T $=10 \mathrm{~K}$ and small time steps in Brownian Dynamics and restraints on solute heavy atoms for 100 ps. The third stage included repetition of the above stage but with restraints on solute heavy atoms for $12 \mathrm{ps}$, the following 4th stage was also carried out in a similar manner with NPT instead of NVT. In stage 5, solvate pockets were focussed. Similar to stage 4, the stage 6 was carried out. The next stage was concerned with simulation at NPT for 24 ps with no restraints. Ultimately, simulations were done.

In this study, Molecular simulations were performed specifically for the top two identified hits to study the stability of the ligand receptor complex for 100 ns. Stability of docked complexes of 'S protein - 8-HDS' and 'M pro - 8-HDS' till $100 \mathrm{~ns}$ simulation time was checked using system builder of Desmond implemented in Maestro [36]. The system for ' $\mathrm{S}$ Protein-8-HDS' and 'M pro-8-HDS' were immersed in a water filled cubic box of $10 \AA$ spacing containing 64002 and 10297 water molecules, respectively, with system builder of the Desmond in the Maestro program using extended simple point charge (SPC). Neutralisation of the docked complex was done by the addition of $2 \mathrm{Na}^{+}$ions $(3.531 \mathrm{mM}$ concentration) with +2 charges into the system for M pro and 8-HDS. Similarly, for S protein 
and 8-HDS neutralization of docked complex was done by addition of $4 \mathrm{Na}^{+}$ions $(1.136 \mathrm{mM}$ concentration) with +4 charges into the system.

Molecular Mechanics Generalized Born Surface Area (MM-GBSA) method has been followed for the calculation of binding free energies of 8-HDS with S Protein and M pro, respectively. The more negative value indicates stronger binding as the MM-GBSA in an index of free energy of binding. Prime module [37] was used to calculate MM-GBSA binding free energy under equilibrated trajectory of molecular dynamics. The potential energy was seen to decline in case of both 'M pro- 8-HDS', 'S protein- 8-HDS' complexes during the $100 \mathrm{~ns}$ which revealed that the system is stable. The different conformations formed over 100 ns simulation period were analysed. The average change in the displacement of selected atoms in a particular frame with respect to reference frame was computed by estimation of Root mean square deviation (RMSD) of protein and ligand over simulation trajectory for 100 ns.

\section{5 pKa Calculations}

PROPKA program is one of the widely used approaches for calculating of $\mathrm{pKa}$ values in proteins. PROPKA generates convenient structural rationalization of the predicted $\mathrm{pKa}$ values. In this program, Graphical User Interface (GUI) tool was employed for computing the $\mathrm{pH}$-dependent properties of proteins such as charge and stabilization energy by providing a direct link between the structure and the pKa data (predicted by the PROPKA calculations, via the Visual Molecular Dynamics (VMD) program) [38]. PROPKA2.0 was used to calculate the $\mathrm{pKa}$ value of $\mathrm{M}$ protease, $\mathrm{S}$ protein and protein ligand complex "S protein- 8HDS" and "M protease - 8-HDS" at pH 7.0.

\subsection{Drug likeliness analysis}

Swiss ADME is a robust web tool to access physicochemical properties, pharmacokinectics, drug-likeliness and medical chemistry friendliness of a molecule to determine its proficiency to be used as a drug. Bioavailability Radar (lipophilicity, size, polarity, solubility, saturation and flexibility) has been used for this purpose to calculate drug-likeness. Assessment of ADME (absorption, distribution, metabolism and excretion) is essential for drug design. The Canonical SMILES of 8-HDS was retrieved from PubChem database and the ADME properties were predicted at Swiss ADME (http://www.swissadme.ch/). 


\section{RESULTS}

\subsection{Structural analysis}

The secondary structure of M protease as predicted from SOPMA (Self Optimised Prediction Method with Alignment) showed that the M protease is composed of 306 amino acid residues consisting of $89 \alpha$ helices (29.08\%), 35 pturns (11.44\%), 99 random coil (32.35\%) and 83 extended strands (27.12\%). It was revealed through ExPASy ProtParam that there are 26 negatively charged (Asp + Glu) and 22 positively charged residues (Arg + Lys). The aliphatic index was determined as 82.12. The GRAVY (Grand Average of Hydropathicity) was found to be -0.019 . The instability index was scored to be 27.65 . These characteristics factually support that the protein is stable.

The estimated half-lives of $\mathrm{M}$ protease in mammalian reticulocytes, yeast and Escherichia coli on a comparative analysis were determined as 1.9 hours, 20 hours and 10 hours, respectively.

\subsection{Sequence analysis}

Multiple sequence alignment of M protease of SARS-CoV2 with the M protease of MERSCoV, HCoV-NL63 and SARS-CoV was done using ClustalW. The sequence identity of M protease of SARS-CoV2 shared up to $40.52 \%, 47.71 \%$ and $96.07 \%$ similarity with M protease of HCoV-NL63, MERS-CoV and SARS-CoV respectively. Thus the results depicted that M protease of SARS-CoV2 shares maximum similarity with the M protease of SARSCoV with only 12 mutated amino acids in comparison to SARS CoV (Table ST3).

\subsection{Structure alignment}

TM-align (https://zhanglab.ccmb.med.umich.edu/TM-align/) structures of M pro of SARSCoV2 and SARS-CoV were superimposed for comparative analysis of structures. Due to maximum sequence similarity, these two viral strains were taken for Structure-Structure superimposition. From structural alignment studies, it was inferred that M protease of SARSCoV2 differs from SARS-CoV in only 12 amino acids which comprises 6 mutations in Domain-I, 1 mutation in Domain-II, 4 mutations in Domain-III and 1 mutation in loop region in between Domain-II and Domain-III. Thus it was deduced from the structure alignment and sequence alignment that SARS-CoV is closely related to SARS-CoV2 (Fig. 1). 


\subsection{S-protein- ACE2 interaction in presence of 8-HDS}

The best 10 docking models with different free energies were obtained from the ClusPro web-server. The total RMSD value was taken as criteria for grouping [39]. Our study analysed 5 ClusPro docking models which were chosen based on probability of S Protein, S Protein with 8-HDS to interact with the predicted binding sites of ACE2 as well as the lowest binding energy during such interactions. Average binding energy of all 5 binding positions for S Protein- ACE2 interaction is $-901.2 \mathrm{~kJ} / \mathrm{mol}$. Nevertheless, average binding energy for $\mathrm{S}$ Protein-ACE2 in presence of 8-HDS is $-771.86 \mathrm{~kJ} / \mathrm{mol}$ (Table 1).

\subsection{Molecular docking analysis}

Analysis of the binding interactions of sanguinarine, eugenol and their derivatives with $\mathrm{S}$ protein and M pro was done using Autodock Vina 1.1.2 [31].

The binding energies were determined as $\Delta \mathrm{Gb}-9.3 \mathrm{Kcal} / \mathrm{mol},-8.3 \mathrm{Kcal} / \mathrm{mol},-9.2 \mathrm{Kcal} / \mathrm{mol}$, $9.4 \mathrm{Kcal} / \mathrm{mol},-7.9 \mathrm{Kcal} / \mathrm{mol}$ and $-9.4 \mathrm{Kcal} / \mathrm{mol}$ when $\mathrm{S}$ protein interacts with sanguinarine, sanguinarine analogue, dihydrosanguinarine, sanguinarinerg, sanguinarineanalogue16 and 8HDS, respectively. In contrast, $\Delta \mathrm{Gb}-9.8 \mathrm{Kcal} / \mathrm{mol},-8.4 \mathrm{Kcal} / \mathrm{mol},-9.5 \mathrm{Kcal} / \mathrm{mol},-8.4$ $\mathrm{Kcal} / \mathrm{mol},-8.3 \mathrm{Kcal} / \mathrm{mol}$ and $-10.3 \mathrm{Kcal} / \mathrm{mol}$ were the energies, respectively, when $\mathrm{M}$ protease interacted with the above molecules. Similarly, the binding affinities scored to be $\Delta \mathrm{Gb}-5.5 \mathrm{Kcal} / \mathrm{mol},-6.7 \mathrm{Kcal} / \mathrm{mol},-5.9 \mathrm{Kcal} / \mathrm{mol},-6.0 \mathrm{Kcal} / \mathrm{mol},-5.9 \mathrm{Kcal} / \mathrm{mol}$ and -6.1 $\mathrm{Kcal} / \mathrm{mol}$ when $\mathrm{S}$ protein interacts with eugenol, benzyleugenol, acetyleugenol, eugenololeate, eugenol propionate and eugenol sulphate, respectively. In contrast, $\Delta \mathrm{Gb}-7.1$ $\mathrm{Kcal} / \mathrm{mol},-8.4 \mathrm{Kcal} / \mathrm{mol},-6.2 \mathrm{Kcal} / \mathrm{mol},-6.4 \mathrm{Kcal} / \mathrm{mol},-6.1 \mathrm{Kcal} / \mathrm{mol}$ and $-6.6 \mathrm{Kcal} / \mathrm{mol}$ were the energies, respectively, when $\mathrm{M}$ protease interacted with the above molecules (Table 2, ST1, ST2).

From the above data, it can be deduced that sanguinarine shows higher binding affinity towards both $\mathrm{M}$ pro and S protein (Table 2). Out of them 8-HDS has the highest binding affinity towards both proteins.

\subsection{Molecular Simulation analysis}

As the best docking results were observed in case of 8-HDSwith both $\mathrm{S}$ protein and $\mathrm{M}$ protease, it was taken further for molecular simulations study. 


\subsubsection{Interaction of $S$ protein with 8-hydroxydihydrosanguinarine}

The average change in displacement of atoms for all frames with respect to the reference frame in trajectory, i.e. protein ligand Root Mean Square Deviation (RMSD) is stable after 40 ns which was recorded to be $2.5 \AA$ (Fig. S8) in 'S protein- 8-HDS' complex. Such changes suggest that the compound, 8-HDS is capable of causing significant conformational changes in the protein during simulation. The plot illustrates, that the RMSD of ligand is smaller than that of protein, which suggests that compound has not diffused away the binding site.

The structural changes in the protein as determined through RMSF plot reveal that maximum fluctuations occur between 300-500 amino acid residues (Fig. S4). It is known to us that S protein's RBD site spans from 319 amino acid to 591 amino acid residues [40]. Therefore it can be deduced that 8-HDS is capable of distorting the RBD site of S protein. The RMSF plot depicts peaks in the regions of $\alpha$-helices and $\beta$-sheets which otherwise show less fluctuations. Thus the compound bears the efficacy to cause extensive conformational changes in the protein. Water bridges, $\mathrm{H}$ - bonds and hydrophobic interactions were involved in proteinligand binding. Consideration of these bonds is quintessential in drug design as they influence drug specificity, metabolisation and absorption.

His1058, Ser730, and Thr778 are seen to interact with ligand over the major time course of $100 \mathrm{~ns}$ trajectory. The hydroxyl group of pyridone ring in 8-HDS is found to be in association with the His 1058 of the protein for 52\% of the 100 ns trajectory. Thr778 and Ser730 interact with the ligand though water bridges for $52 \%$ and $33 \%$ of the trajectory, respectively (Fig. S5).

\subsubsection{Interaction of $M$ protease with 8-hydroxydihydrosanguinarine}

The Root Mean Square Deviation (RMSD) of the M pro - 8-HDS complex was found to be $1.25 \AA$ (Fig. 2). Though the protein ligand interaction occurs over $100 \mathrm{~ns}$ simulation time yet substantial interaction was observed in the first $10 \mathrm{~ns}$ and in between 85-100 ns.

The RMSF exhibited the highest peak near the 50 amino acid residues which is an $\alpha$ - helix region (Fig. S3). As $\alpha$-helix is known to determine the functional aspects, perturbations in this region make the protein feeble in its action. Generally the fluctuations appear in the $\mathrm{N}$ and the C- terminal ends but peaks appearing all over the RMSF plot ensure that the 
compound is capable of destabilising the protein by causing conformational changes. Water bridges, H-bond and hydrophobic interactions which play a decisive role in ligand binding are persistent in this protein ligand interaction. Phe294 is observed to be involved in maximum interaction time i.e. about 75\% (Fig. S7). Asp295 shows dual interaction with hydroxyl group of pyridone of 8-HDS through double water bridges one for $34 \%$ and another for $30 \%$ of simulation time. Asn 151 also interacts with the ligand for $40 \%$ of the simulation time (Fig. 3). The information derived above from simulation study is also supported by wellaligned superimposition of 8-HDS on M Pro during 0-100 ns simulation. Amino acids Phe8, Asn151, Ile152, Asp153, Phe294, Val297, Arg298, Val303 interact with M Pro all over the simulation trajectory 0-100 ns, where 10 and $80 \mathrm{~ns}$ simulation trajectories show interaction of maximum 17 amino acids with 8-HDS. The minimum interactions are observed at 0 and 100 ns with 11 and 10 amino acids, respectively [67] (Fig. 4, S9, S10).

\section{7 pKa Calculations of M protease, S Protein and its complex with 8-HDS}

Four maximum $\mathrm{pK}_{\mathrm{a}}$ and $\mathrm{pKa}$ shift values of amino acid residues of $\mathrm{M}$ pro and $\mathrm{S}$ protein in presence or absence of 8-HDS were retrieved by PROPKA2. Amino acid residues Tyr161, Tyr54, His163 and His164 showed $\mathrm{pK}_{\mathrm{a}}$ shift values 5.5, 5.2, -4.8 and -4.8, respectively in native $\mathrm{M}$ pro at $\mathrm{pH}$ 7.0. It was observed that $\mathrm{pK}_{\mathrm{a}}$ shift values of all four Amino acid residues changed to 5.3, 5.7, -5.8 and -4.9, respectively during interaction with 8-HDS (Fig. 5, Table. ST5). $\mathrm{pK}_{\mathrm{a}}$ and pka shift values remain constant for S-protein as well as S-protein-8-HDS complex.

\subsection{Drug likeliness analysis}

SwissADME tool has been used to investigate the drug-likeness property of the lead molecule i.e 8-HDS. This tool interprets the relationship between pharmacokinetic and physicochemical parameters of the lead molecule. The physicochemical properties of 8-HDS $\left(\mathrm{C}_{20} \mathrm{H}_{15} \mathrm{NO}_{5}\right)$ were determined i.e. - $349.3 \mathrm{~g} / \mathrm{mol}$ molecular weight, 26 heavy atoms, 5 hydrogen bond acceptors, 1 hydrogen bond donor, molar refractivity of 97.86, no rotatable bonds and topological polar surface area of $60.39 \AA^{2}$. The average lipophilicity score of iLOGP, XLOGP3, WLOGP, MLOGP and SILICOS-IT models computes to 3.03 . Bioavailability Score of the molecule is 0.55 . It is observed that 8 -HDS has moderate solubility in water. SwissADME has five different rules (Lipinski, Ghose, Veber, Egan, Muegge) to predict drug-likeness, all 5 models render 8-HDS the competence for an effective drug molecule (Table ST4). 


\section{DISCUSSION}

In this study we have primarily analysed the molecular interactions of $\mathrm{S}$ protein and $\mathrm{M}$ protease with 8-HDS through an insilico approach. Inspecting the sequential and structural alignment through various computational tools enhances our concept for better understanding of SARS-CoV2.

Here it was inferred from sequence similarity study that M protease of SARS-CoV2 shows $96 \%$ sequential identity with that of SARS-CoV. Thus the sequence similarities confirm that SARS-CoV2 is a descendant from SARS-CoV. Evolutionary studies state that SARS-CoV2 is more closely related to SARS-CoV which had infected several people in the year 2003 with $\sim 10 \%$ fatality rate of [41] than MERS-CoV that had caused infection in 2012 with a fatality rate of $\sim 36 \%[42]$.

Because of their potential capability to fit into different environments and susceptibility to recombination and mutation, Coronaviruses can deliberately adapt to altered host range and tissue tropism [43]. The major concern now is to contain the spread of virus. Blocking the viral infection in cells through $\mathrm{M}$ protease inhibition and targeting the viral spike protein to prevent its attachment and entry into host cells can serve as approaches to combat against the virus. These present phytocompounds, eugenol and sanguinarine, as well as their derivatives are to be employed for the above purpose.

While the principal natural source of eugenol is clove (Syzygium aromaticum) [44], it can also be extracted from soybeans, mung beans [45], coffee [46], bananas [47] and herbs such as nutmeg (Myristica fragrans), cinnamon (Cinnamomum verum) and basil (Ocimum basilicum) [48]. It is used in a variety of pharmaceutical products due to its antioxidant, anticarcinogenic, cytotoxic, antitumor [49], anti-inflammatory [50] and antibacterial [51] properties. This compound was tested against viral isolates of different strains of the Herpes virus (HSV) providing protection in varying degrees [52-54]. Eugenol also exhibits antiviral properties against Herpes Simplex virus type 1 and 2, feline calicivirus, tomato yellow leaf curl virus, Influenza A virus, and four airborne phages [55]. 
Extracted from the roots of Sanguinaria canadensis and other poppy-fumaria species, sanguinarine bears antitumor [56], anti-bacterial [57,58], antifungal [59] and antiinflammatory properties [60] and is known to inhibit neutrophil function such as degranulation and phagocytosis in vitro[61]. This benzophenanthridine alkaloid serves as inhibitor of protein kinase $\mathrm{C}$ bearing structural homology with chelerythrine[62]. 8-HDS possesses a pyridone ring which bears the capacity to inhibit viral enzymes essential for its replication. Due to such antiviral properties of pyridones, they can be taken as ideal molecules for drug development [63]. Zhang et al 2020 have also suggested that pyridonecontaining inhibitors can serve for the development of effective therapeutic anti-coronaviral drugs [15].

The molecular docking experiments demonstrated the binding affinity of sanguinarine, eugenol and their derivatives with $\mathrm{S}$ protein and $\mathrm{M}$ protease. It was witnessed that 8-HDS showed the highest affinity with $S$ protein and $M$ protease with energies $\Delta \mathrm{Gb}-9.4 \mathrm{Kcal} / \mathrm{mol}$ and $\Delta \mathrm{Gb}-10.3 \mathrm{Kcal} / \mathrm{mol}$ respectively. The binding of 8 -HDS with $\mathrm{S}$ protein is facilitated by several bonds and interactions such as Vander Waal's (Ser596, Pro665, Ile666, Gly667); Carbon Hydrogen Bond (Thr768); Conventional Hydrogen Bond (Gln314); Pi- Cation (Lys733); Pi- Sigma (Ile312, Val772); Pi-Pi T Shaped (Tyr313); Pi-Alkyl (Ile312, Pro862, Leu861) (Fig. 9 (A,B)) (Table 1). Similarly, "M protease - 8-HDS" complex are involved with various interactions, such as Vander Waal's interaction (Gly138, Ser139); Carbon Hydrogen Bonds (Glu288); Conventional Hydrogen Bonds (Lys5); Unfavourable Donor Donor (Gln127); Unfavourable Acceptor Acceptor (Lys5); Pi- Anion (Glu290); Pi-Pi Stacked (Tyr126); Pi- Alkyl (Lys137) (Fig. 8 (A,B)) (Table 2). Molecular Dynamics (MD) simulations were conducted to investigate the physical perturbations in the protein ligand conformation. It explores the structural and functional aspects of biological macromolecules. MD simulations exhibit flexibility of intrinsic receptors and also include treatment of water molecules rather than simple portrayal of ligand -protein interactions. Therefore, MD simulations prove to be effective in studying atomic level interactions and establishing the ligand selectivity towards the target. 8-HDS possesses the capability to fluctuate the RBD site of S protein, which interacts with ACE2 receptor of human cell for the viral infection [20]. Structural fluctuation at RBD site may inhibit the binding of S protein and ACE2 receptor, which eventually prevent the viral infection in human cell. It was observed that during protein-protein interaction, binding energy of S Protein- ACE2 decreases in presence of the phytocompound, (i.e. 8-HDS). A significant decline of $129.34 \mathrm{~kJ} / \mathrm{mol}$ of binding energy was 
observed during the interaction of S Protein- ACE2 in presence of 8-HDS compared to their direct binding. Therefore, it can be presumed that 8-HDS is capable of hindering the attachment of RBD site of S Protein to the ACE2 receptor protein (Fig. 6, 7). This would indeed pave a way for the utilisation of 8-HDS in repurposing/design of effective therapy to prevent the viral entry.

From molecular docking interaction study, 8-HDS exhibit best binding affinity towards $\mathrm{M}$ protease i.e. $-10.3 \mathrm{kcal} / \mathrm{mol}$. Molecular simulation analysis depicts that 8 -HDS fluctuates the alpha helical secondary structure of $\mathrm{M}$ protease. Disturbance in helix regions cause distortion of intra and inter molecular hydrogen bonding network. Such structural changes of alpha helix in $\mathrm{M}$ protease may cause unfolding and making it non-functional. Maximum MMGBSA binding energy was found to be $-60 \mathrm{Kcal} / \mathrm{mol}$ at $10 \mathrm{~ns}$ for $\mathrm{S}$ Protein-8-HDS complex and lowest MM-GBSA energy was $-47 \mathrm{Kcal} / \mathrm{mol}$ at $60 \mathrm{~ns}$ with average MM-GBSA binding energy $-52.22 \mathrm{Kcal} / \mathrm{mol}$. Similarly, for M pro - 8-HDS complex maximum MM-GBSA binding energy was $-50 \mathrm{Kcal} / \mathrm{mol}$ at $80 \mathrm{~ns}$ and lowest was observed to be $-35 \mathrm{Kcal} / \mathrm{mol}$ at 20 ns with average MM-GBSA binding energy $-42.54 \mathrm{Kcal} / \mathrm{mol}$ (Fig. S6).

The hydrophobic amino acids are the main dynamic force in protein folding. In general, proteins become functional after being folded into specific globular structure. During protein folding, hydrophobic amino acids get buried in the core of the protein to get protected from water, leading to the protein fold stable [67,68]. Phe8, Ile152, Phe294, Val297, Val303 hydrophobic Amino acids of M Pro generally interact with 8-HDS during the $100 \mathrm{~ns}$ simulation which caused instability in the protein [67] (Fig. S10).

In some recent studies, many natural compounds have been evaluated via molecular docking to analyse the binding affinity of these compounds with $\mathrm{CoV}$ proteins with respect to antiviral drugs. This serves as a prospective to evaluate the likelihood of these molecules as drug candidates. Sampangi-Ramaiah et. al., 2020 have assessed binding affinities of 27 natural products towards proteases of COVID-19, out of which 15 compounds showed permissible results i.e. they possess more binding energy than the threshold $-6.0 \mathrm{kcal} / \mathrm{mol}$. They also observed the highest affinities in Glabridin $(-8.0 \mathrm{kcal} / \mathrm{mol})$ and Glucobrassin $(-8.1 \mathrm{kcal} / \mathrm{mol})$ which were reasonable to compare with Sanquinavir $(-9.2 \mathrm{kcal} / \mathrm{mol})$, the synthetic antiviral drug, as a positive control. Similarly, Suravajhala et. al. (2020) have conducted molecular docking of 14 drug candidates with SARS-CoV2 protein in which curcumin showed good binding affinity with nucleocapsid $(-8.75 \mathrm{kcal} / \mathrm{mol})$ and nsp10 $(-7.85 \mathrm{kcal} / \mathrm{mol})$, compared to ivermectin, azithromycin and remedesivir [24]. 
Meanwhile, in our present study, the anticipating drug molecule, 8-HDS shows even greater binding affinities towards the $\mathrm{S}$ protein $(-9.4 \mathrm{kcal} / \mathrm{mol})$ and $\mathrm{M}$ pro $(-10.3 \mathrm{kcal} / \mathrm{mol})$. This definitely renders the molecule more likelihood to be accepted as an anti-CoV drug.

Molecular simulation analysis corroborates docking studies revealing that 8-HDS can efficiently destabilise the $\mathrm{S}$ protein and $\mathrm{M}$ protease thereby inhibiting their functions. In a more recent study, Zhang et. al. 2020 [20] have opined that pyridone containing ligand can potentially improve the half-life of the compound in plasma thus development of the pyridone containing inhibitor would play an important role towards the development of anti coronaviral drug. It is therefore quite reasonable that the pyridone containing sanguinarine derivative, 8-HDS reported in this study can be a potent molecule in preventing the entry as well as replication of SARS CoV2.

For a molecule to be an effective drug, it needs to reach the target in optimised concentration and be available in bioactive form till the necessary biological events occur. The SwissADME technology makes the process of drug discovery with less time and resource consuming. Appraisal of the structural or physicochemical properties of development compounds for drug-likeness is enough to consider it as an oral drug-candidate [64]. Druglikeness of a molecule is evaluated with respect to bioavailability by qualitatively examining the probability of the molecule to be developed into an oral drug.

The pink core area of bioavailability Radar representing lipophilicity, size, polarity, solubility, saturation and flexibility define the optimal range of properties for drug-likeness of the input molecule, 8-HDS (Fig. 10) (Table ST4). Due to zero rotatable bonds 8-HDS have no Bioavailability Radar in the flexibility region. The BOILED-Egg model [65] predicts easy penetration of 8-HDS through blood-brain barrier (BBB) and human gastrointestinal absorption (HIA). From the Physicochemical, Lipophilicity, Water Solubility, Pharmacokinetics, Drug-likeness properties of 8-HDS, the study arrives at a conclusion that 8 -HDS could be a potential drug. The resulting changes in protonation of M pro are in good agreement that the protein structure undergoes significant structural changes at neutral $\mathrm{pH}$ [66]. Our study primarily focuses on 8-HDS which can be a promising drug molecule against SARS-CoV2 due to the presence of a pyridone ring. This phytocompound is known for its antiviral properties and shows drug likeness, structural alteration, binding affinity and molecular interaction. These findings infer that 8-HDS could serve as an effective and potential drug molecule. 


\section{CONCLUSION}

The COVID-19 pandemic has become a global consternation by infecting millions of people worldwide, claiming several thousand lives and having shaken the socio-economic stability. It calls for an urge to stop the march of rapidly dwindling scourge. Our research via computational tools establishes that 8-hydroxydihydrosanguinarine can be an efficient inhibitor in blocking viral infection. Thus it can prove to be a potential molecule in therapeutic drug development against COVID-19.

\section{ACKNOWLEDGEMENTS}

Authors are thankful to the World Bank-OHEPEE (Odisha Higher Education Program for Excellence and Equity), Department of Higher Education, Govt of Odisha for supporting Centre of Excellence in Integrated in Omics and Computational Biology, Utkal University. Support from DBT Government of India, New Delhi to Department of Biotechnology, Utkal University is gratefully acknowledged.

Conflict of Interest: Authors declare no conflict of interest

\section{References}

1. F.A. Rabi, M.S. Al Zoubi, G.A. Kasasbeh, D.M. Salameh, \& A.D. Al-Nasser, SARSCoV-2 and Coronavirus Disease 2019: What We Know So Far, Pathogens. 9 (2020) 231, https://doi.org/10.3390/pathogens9030231

2. P. Zhou, X.L. Yang, X.G. Wang, B. Hu, L. Zhang, W. Zhang, Z.L. Shi, A pneumonia outbreak associated with a new coronavirus of probable bat origin, Nature. (2020), https://doi.org/10.1038/s41586-020-2012-7.

3. F. Wu, S. Zhao, B. Yu, Y.M. Chen, W. Wang, Z.G. Song, Y.Z. Zhang, A new coronavirus associated with human respiratory disease in China, Nature. (2020), https://doi.org/10.1038/s41586-020-2008-3.

4. S. Dong, J. Sun, Z. Mao, L. Wang, Y.L. Lu, \& J. Li, A guideline for homology modeling of the proteins from newly discovered betacoronavirus, 2019 novel coronavirus (2019-nCoV), J. Med. Virol. (2020), https://doi.org/10.1002/jmv.25768

5. S.F. Ahmed, A.A. Quadeer, M.R. McKay, Preliminary identification of potential vaccine targets for the COVID-19 coronavirus (SARS-CoV-2) based on SARS-CoV immunological studies, Viruses. 12 (2020) 254, https://doi.org/10.3390/v12030254.

6. Lu, R. et al, Genomic characterisation and epidemiology of 2019 novel coronavirus: Implications for virus origins and receptor binding, Lancet. 395 (2020) 565-574, https://doi.org/10.1016/S0140-6736(20)30251-8. 
7. M.U. Mirza, \& M. Froeyen, Structural elucidation of SARS-CoV-2 vital proteins: Computational methods reveal potential drug candidates against main protease, Nsp12 polymerase and Nsp13 helicase, J. Pharm. Anal. (2020), https://doi.org/10.1016/ j.jpha.2020.04.008

8. W. Dai, B. Zhang, H. Su, et al., Structure-based design of antiviral drug candidates targeting the SARS-CoV-2 main protease published online ahead of print, Science. (2020) eabb4489, https://doi.org/10.1126/science.abb4489.

9. A. R. Fehr, \& S. Perlman, Coronaviruses: An Overview of Their Replication and Pathogenesis, Methods Mol Biol. (2015) 1-23, https://doi.org/10.1007/978-1-49392438-7_1

10. M. Prajapat, P. Sarma, N. Shekhar, A. Prakash, P. Avti, A. Bhattacharyya, H. Kaur, S. Kumar, S. Bansal, A. R. Sharma, B. Medhi, Update on the target structures of SARSCoV-2: A systematic review, Indian J Pharmacol. 52 (2020) 142-149, https://doi.org/10.4103/ijp.IJP_338_20

11. X. Xue, H. Yang, W. Shen, Q. Zhao, J. Li, K. Yang, Z. Rao, Production of Authentic SARS-CoV Mpro with Enhanced Activity: Application as a Novel Tag-cleavage Endopeptidase for Protein Overproduction, J. Mol. Biol. 366 (2007) 965-975, https://doi.org/10.1016/j.jmb.2006.11.073

12. K. Anand, Structure of coronavirus main proteinase reveals combination of a chymotrypsin fold with an extra alpha-helical domain, EMBO J. 21 (2002) 32133224, https://doi.org/10.1093/emboj/cdf327

13. J. Shi, Z. Wei, \& J. Song, Dissection Study on the Severe Acute Respiratory Syndrome 3C-like Protease Reveals the Critical Role of the Extra Domain in Dimerization of the Enzyme, J. Biol. Chem. 279 (2004) 24765-24773, https://doi.org/10.1074/jbc.m311744200

14. X. Xue, H. Yu, H. Yang, F. Xue, Z. Wu, W. Shen, Z. Rao, Structures of Two Coronavirus Main Proteases: Implications for Substrate Binding and Antiviral Drug Design, J. Virol. 82 (2007) 2515-2527, https://doi.org/10.1128/jvi.02114-07.

15. L. Zhang, D. Lin, X. Sun, U. Curth, C. Drosten, L. Sauerhering, R. Hilgenfeld, Crystal structure of SARS-CoV-2 main protease provides a basis for design of improved $\alpha$-ketoamide inhibitors, Science. (2020) eabb3405, https://doi.org/10.1126/science.abb3405

16. A. Zumla, J. F.W. Chan, E.I. Azhar, D.S.C. Hui, \& K.Y. Yuen, Coronaviruses drug discovery and therapeutic options, Nat. Rev. Drug Discov. 15 (2016) 327-347, https://doi.org/10.1038/nrd.2015.37

17. A.T. Ton, F. Gentile, M. Hsing, F. Ban, \& A. Cherkasov, Rapid Identification of Potential Inhibitors of SARS-CoV-2 Main Protease by Deep Docking of 1.3 Billion Compounds, Mol Inform. (2020), https://doi.org/10.1002/minf.202000028

18. I. L. Lu, N. Mahindroo, P. H. Liang, Y. H. Peng, C. J. Kuo, K. C. Tsai, S. Y. Wu, Structure-Based Drug Design and Structural Biology Study of Novel Nonpeptide Inhibitors of Severe Acute Respiratory Syndrome Coronavirus Main Protease, J. Med. Chem. 49 (2006) 5154-5161, https://doi.org/10.1021/jm060207o

19. J. E. Blanchard, N. H. Elowe, C. Huitema, P. D. Fortin, J. D. Cechetto, L. D. Eltis, \& E. D. Brown, High-Throughput Screening Identifies Inhibitors of the SARS 
Coronavirus Main Proteinase, Chem. Biol. 11 (2004) 1445-1453, https://doi.org/10.1016/j.chembiol.2004.08.011

20. A. B Jena, N. Kanungo, V. Nayak, G. B. N Chainy, J. Dandapat, Catechin and curcumin interact with S protein of SARS-CoV2 and ACE2 of human cell membrane: insights from computational studies. Sci Rep. (2021); 11(1):2043. doi: 10.1038/s41598-021-81462-7. PMID: 33479401.

21. J.F. Riordan, Angiotensin-I-converting enzyme and its relatives, Genome Biol. 4 (2003) 225, https://doi.org/10.1186/gb-2003-4-8-225

22. C. Wu, Y. Liu, Y. Yang, P. Zhang, W. Zhong, Y. Wang, H. Li, Analysis of therapeutic targets for SARS-CoV-2 and discovery of potential drugs by computational methods, Acta Pharm. Sin. B. (2020), https://doi.org/10.1016/j.apsb.2020.02.008

23. M.H. Sampangi-Ramaiah, R. Vishwakarma, R.U. Shaanker, Molecular docking analysis of selected natural products from plants for inhibition of SARS-CoV-2 main protease, Curr. Sci. 118 (2020) 7.

24. R. Suravajhala, A. Parashar, B. Malik, A. V. Nagaraj, G. Padmanaban, P. K. Kishor, R. Polavarapu, P. Suravajhala, Comparative Docking Studies on Curcumin with COVID-19 Proteins, Preprints. (2020) 2020050439, https://doi.org/10.20944/preprints202005.0439. v1.

25. K.-M. Cho, I.-D. Yoo, \& W.-G. Kim, 8-Hydroxydihydrochelerythrine and 8Hydroxydihydrosanguinarine with a Potent Acetylcholinesterase Inhibitory Activity from Chelidonium majus L, Biol Pharm Bull. 29 (2006) 2317-2320, https://doi.org/10.1248/bpb.29.2317.

26. I. Mackraj, T. Govender, \& P. Gathiram, Sanguinarine. Cardiovasc. Drug Rev. 26 (2008) 75-83, https://doi.org/10.1111/j.1527-3466.2007.00037.x

27. P. S. Dragovich, T. J. Prins, R. Zhou, T. O. Johnson, Y. Hua, H. T. Luu, R. A. Ferre, Structure-Based Design, Synthesis, and Biological Evaluation of Irreversible Human Rhinovirus 3C Protease Inhibitors. 8. Pharmacological Optimization of Orally Bioavailable 2-Pyridone-Containing Peptidomimetics, J. Med. Chem. 46 (2003) 4572-4585, https://doi.org/10.1021/jm0301661.

28. Z. Lv, C. Sheng, T. Wang, Y. Zhang, J. Liu, J. Feng, K. Li, Design, Synthesis, and Anti hepatitis B Virus Activities of Novel 2-Pyridone Derivatives, J. Med. Chem. 53 (2010) 660-668, https://doi.org/10.1021/jm901237x

29. D. Kozakov, D. R Hall, B. Xia, K. A. Porter, D. Padhorny, C. Yueh, S. Vajda, The ClusPro web server for protein-protein docking, Nat. Protoc. 12 (2017), 255-278. https://doi:10.1038/nprot.2016.169

30. E. F. Pettersen, T. D. Goddard, C. C. Huang, G. S. Couch, D. M. Greenblatt, E. C. Meng, T. E. Ferrin, UCSF Chimera a visualization system for exploratory research and analysis, J Comput Chem. 25 (2004) 1605-1612. 
31. O. Trott, A. J. Olson, AutoDockVina: Improving the speed and accuracy of docking with a new scoring function, efficient optimization, and multithreading, J. Comput. Chem. 31 (2009) 455-461.

32. Dassault Systemes BIOVIA, Discovery Studio Modeling Environment, Release 2017, San Diego: Dassault Systèmes (2016).

33. Schrödinger Release 2020-2: LigPrep, Schrödinger, LLC, New York, NY(2020).

34. R. A. Friesner, R. B. Murphy, M. P. Repasky, L. L. Frye, J. R. Greenwood, T. A. Halgren, P. C. Sanschagrin, D. T. Mainz, Extra Precision Glide: Docking and Scoring Incorporating a Model of Hydrophobic Enclosure for Protein-Ligand Complexes, J. Med. Chem. 49 (2006) 6177-6196.

35. Schrödinger Release 2020-2: Desmond Molecular Dynamics System, D. E. Shaw Research, New York, NY. Maestro-Desmond Interoperability Tools, Schrödinger, New York, NY (2020).

36. Schrödinger Release 2020-2: Maestro, Schrödinger, LLC, New York, NY (2020).

37. Schrodinger Release 2018-2: Prime, Schrodinger. Schrodinger, LLC, New York, NY (2018).

38. M. Rostkowski, M. H. Olsson, C. R. Søndergaard, \& J. H Jensen, Graphical analysis of $\mathrm{pH}$-dependent properties of proteins predicted using PROPKA, BMC structural biology, 11(2011) 6. https://doi.org/10.1186/1472-6807-11-6

39. M. Pi, K. Kapoor, R. Ye, S. K. Nishimoto, J. C. Smith, J. Baudry, \& L. D. Quarles, Evidence for Osteocalcin Binding and Activation of GPRC6A in $\beta$-Cells. Endocrinology. 157(2016), 1866-1880. https://doi:10.1210/en.2015-2010

40. D. Wrapp, N. Wang, K. S. Corbett, J. A. Goldsmith, C. L. Hsieh, O. Abiona, B. S. Graham, J. S. McLellan, Cryo-EM structure of the 2019-CoV spike in the prefusion conformation, Science. 367 (2020) 1260-1263, https://doi.org/10.1126/science. abb2507.

41. F. Li, Structure, function, and evolution of coronavirus spike proteins, Annu Rev Virol. 3 (2016) 237-261, https://doi.org/10.1146/annurev-virology-110615-042301.

42. A. Bleibtreu, M. Bertine, C. Bertin, N. Houhou-Fidouh, \& B. Visseaux, Focus on Middle East respiratory syndrome coronavirus (MERS-CoV), Med Maladies Infect. (2019), https://doi.org/10.1016/j.medmal.2019.10.004

43. R. L. Graham, \& R. S. Baric, Recombination, reservoirs, and the modular spike: Mechanisms of coronavirus cross-species transmission, J. Virol. 84 (2010) 3134 3146, https://doi.org/10.1128/JVI.01394-09.

44. D. Bezerra, G. Militão, M. D. Morais, \& D. D. Sousa, The Dual Antioxidant/ Prooxidant Effect of Eugenol and Its Action in Cancer Development and Treatment, Nutrients. 9 (2017) 1367, https://doi.org/10.3390/nu9121367.

45. K.G. Lee, \& T. Shibamoto, Antioxidant Properties of Aroma Compounds Isolated from Soybeans and Mung Beans, J Agr Food Chem. 48 (2000) 4290-4293, https://doi.org/10.1021/jf000442u

46. G. Charalambous, The Quality of Foods and Beverages V2: Chemistry and Technology, 1st ed, Academic Press: New York, NY, USA, 1981; p. 408.

47. M. J. Jordan, K. Tandon, P. E. Shaw, \& K. L. Goodner, Aromatic Profile of Aqueous Banana Essence and Banana Fruit by Gas Chromatography-Mass Spectrometry (GC- 
MS) and Gas Chromatography-Olfactometry (GC-O), J Agr Food Chem. 49 (2001) 4813-4817, https://doi.org/10.1021/jf010471k.

48. G. P. Kamatou, I. Vermaak, \& A. M. Viljoen, Eugenol-From the Remote Maluku Islands to the International Market Place: A Review of a Remarkable and Versatile Molecule, Molecules. 17 (2012) 6953-6981, https://doi.org/10.3390/molecules17066953

49. D. Bezerra, G. Militão, M. D Morais, \& D. D Sousa, The Dual Antioxidant/ Prooxidant Effect of Eugenol and Its Action in Cancer Development and Treatment, Nutrients. 9 (2017) 1367, https://doi.org/10.3390/nu9121367

50. A. Marchese, R. Barbieri, E. Coppo, I. E. Orhan, M. Daglia, S. F. Nabavi, M. Ajami, Antimicrobial activity of eugenol and essential oils containing eugenol: A mechanistic viewpoint, Crit. Rev. Microbiol. $43 \quad$ (2017) 668-689. https://doi.org/10.1080/1040841x.2017.1295225

51. F. Chen, Z. Shi, K. G. Neoh, \& E. T. Kang, Antioxidant and antibacterial activities of eugenol and carvacrol-grafted chitosan nanoparticles, Biotechnol. Bioeng. 104 (2009) 30-39, https://doi.org/10.1002/bit.22363.

52. Y. Tragoolpua, A. Jatisatienr, Anti-herpes simplex virus activities of Eugenia caryophyllus (Spreng.) Bullock \& S. G. Harrison and essential oil, eugenol, Phytother Res. 21 (2007) 1153-8, https://doi.org/10. 1002/ptr.2226 PMID: 17628885.

53. F. Benencia, M. C. Courreges, In vitro and in vivo activity of eugenol on human herpesvirus, Phytother Res. 14 (2000) 495-500, https://doi.org/10.1002/10991573(200011)14:7<495::aid-ptr650>3.0.co;2-8

54. J. Serkedjieva, S. Ivancheva, Antiherpes virus activity of extracts from the medicinal plant Geranium sanguineum L, J Ethno pharmacol. 64 (1999) 59-68, https://doi.org/10.1016/s0378-8741(98)00095-6.

55. T. Lane, M. Anantpadma, J. S. Freundlich, R. A. Davey, P. B. Madrid, \& S. Ekins, The Natural Product Eugenol Is an Inhibitor of the Ebola Virus In Vitro, Pharm. Res. 36 (2019) https://doi.org/10.1007/s11095-019-2629-0.

56. M. Wink, Allelochemical Properties or the Raison D'être of Alkaloids, The Alkaloids: Chemistry and Pharmacology, Chapter 1. (1993) 1-118, https://doi.org/10.1016/s0099-9598(08)60134-0

57. G. Y. Zuo, F. Y. Meng, X. Y. Hao, Y. L. Zhang, G. C. Wang, \& G. L. Xu, Antibacterial Alkaloids from Chelidonium Majus Linn (Papaveraceae) Against Clinical Isolates of Methicillin-Resistant Staphylococcus Aureus, J Pharm Pharm Sci. 11 (2009) 90, https://doi.org/10.18433/j3d30q.

58. G.Y. Zuo, F.Y. Meng, J. Han, X.Y. Hao, G.C. Wang, Y.L. Zhang, \& Q. Zhang, In Vitro Activity of Plant Extracts and Alkaloids against Clinical Isolates of ExtendedSpectrum b-Lactamase (ESBL)-Producing Strains, Molecules. 16 (2011) 5453-5459, https://doi.org/10.3390/molecules16075453.

59. F. Meng, G. Zuo, X. Hao, G. Wang, H. Xiao, J. Zhang, \& G. Xu, Antifungal activity of the benzo[c]phenanthridine alkaloids from Chelidonium majus Linn against resistant clinical yeast isolates, J. Ethnopharmacol. 125 (2009) 494-496, https://doi.org/10.1016/j.jep.2009.07.029 
60. J. Lenfeld, M. Kroutil, E. Maršálek, J. Slavík, V. Preininger, \& V. Simánek, Antiinflammatory Activity of Quaternary Benzophenanthridine Alkaloids fromChelidonoum majus, Planta Medica. 43 (1981) 161-165, https://doi.org/10.1055/s-2007-971493

61. S. Agarwal, M. A. Reynolds, S. Pou, D. E. Peterson, J. A. Charon, \& J. B. Suzuki, The effect of sanguinarine on human peripheral blood neutrophil viability and functions, Oral Microbiol Immun. 6 (1991) 51-61, https://doi.org/10.1111/j.1399302x.1991.tb00451.x

62. J. M. Herbert, J. M. Augereau, J. Gleye, \& J. P. Maffrand, Chelerythrine is a potent and specific inhibitor of protein kinase C, Biochem Bioph Res Co. 172 (1990) 993-999, https://doi.org/10.1016/0006-291x(90)91544-3

63. Dragovich, P. S., Prins, T. J., Zhou, R., Johnson, T. O., Hua, Y., Luu, H. T., Ferre, R. A. (2003). Structure-Based Design, Synthesis, and Biological Evaluation of Irreversible Human Rhinovirus 3C Protease Inhibitors. 8. Pharmacological Optimization of Orally Bioavailable 2-Pyridone-Containing Peptidomimetics. Journal of Medicinal Chemistry, 46(21), 4572-4585. https://doi.org/10.1021/jm0301661.

64. A. Daina, O. Michielin, \& V. Zoete, SwissADME: a free web tool to evaluate pharmacokinetics, drug-likeness and medicinal chemistry friendliness of small molecules, Sci. Rep. 7 (2017), https://doi.org/10.1038/srep42717.

65. A. Daina, \& V. Zoete, A BOILED-Egg To Predict Gastrointestinal Absorption and Brain Penetration of Small Molecules, Chem Med Chem. 11 (2016) 1117-1121.

66. D. C, Bas, D. M. Rogers, \& J. H. Jensen, Very fast prediction and rationalization of pKa values for protein-ligand complexes, Proteins: Structure, Function, and Bioinformatics, 73 (2008). 765-783. https://doi:10.1002/prot.22102

67. A. B, Jena, R. R, Samal, K, Kumari, J. Pradhan, G. Chainy, U. Subudhi, S. Pal, \& J. Dandapat, The benzene metabolite p-benzoquinone inhibits the catalytic activity of bovine liver catalase: A biophysical study, International journal of biological macromolecules, (2020) S0141-8130(20)34969-2.. https://doi.org/10.1016/j.ijbiomac. 2020.11.044.

68. E. D, Van, A. Hoogeveen, \& S. Abeln, The hydrophobic temperature dependence of amino acids directly calculated from protein structures, PLoS computational biology, 11(2015). e1004277. https://doi.org/10.1371/journal.pcbi.1004277 


\section{Figure and Tables}

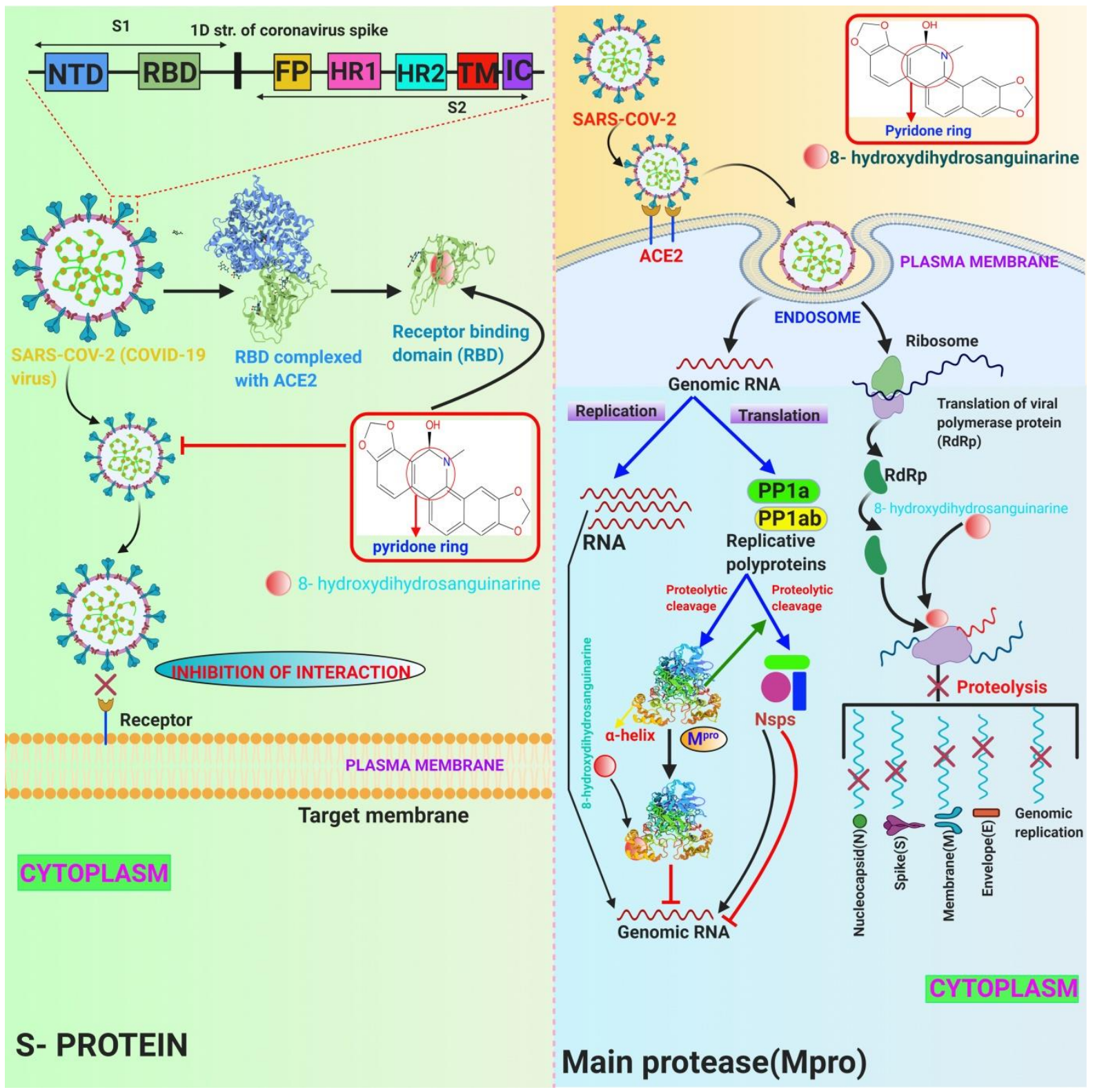

\section{Graphical Abstract}




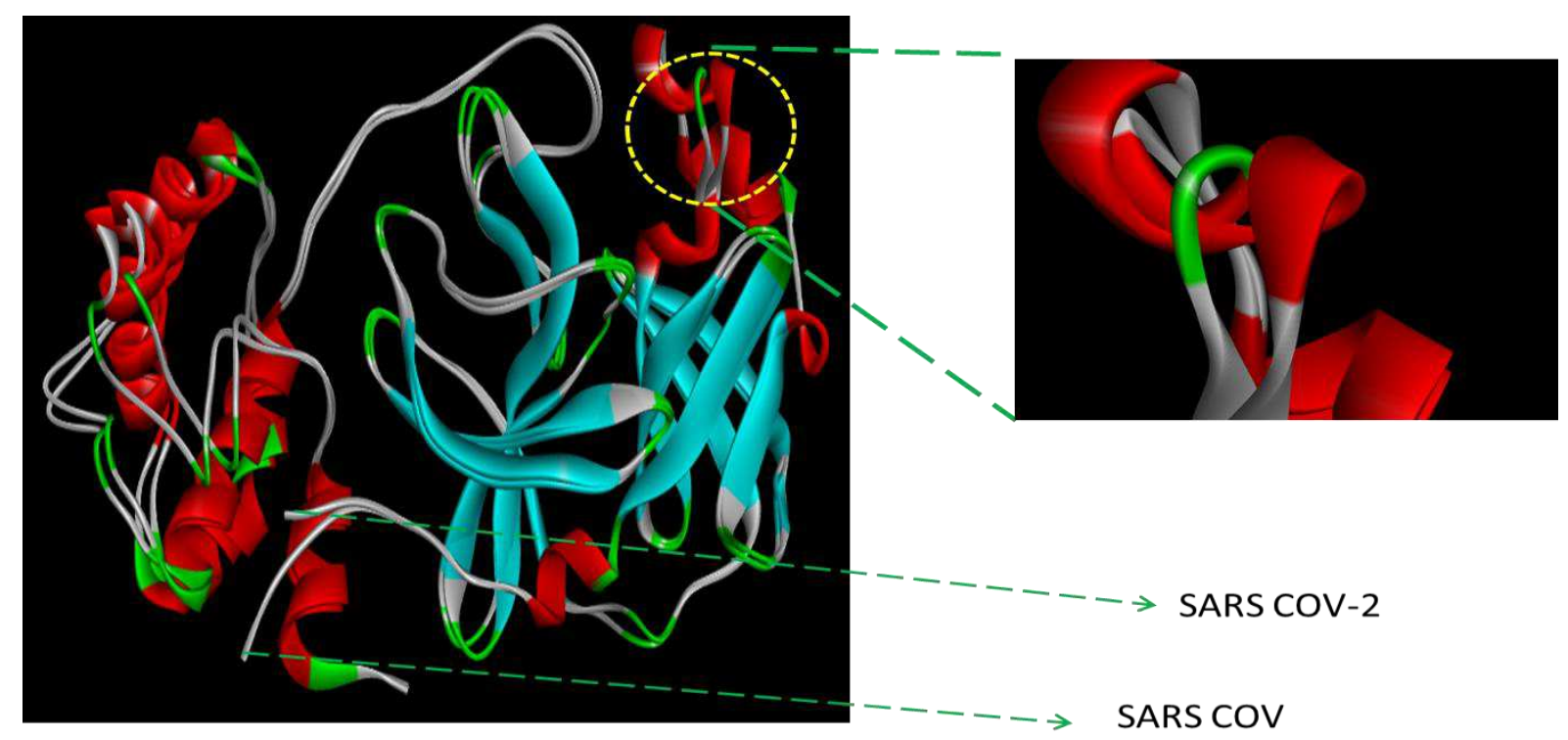

Fig. 1: Structure- Structure alignment by superimposition of $M$ protease of 2019-nCoV on SARS-CoV.

\section{Protein-Ligand RMSD}

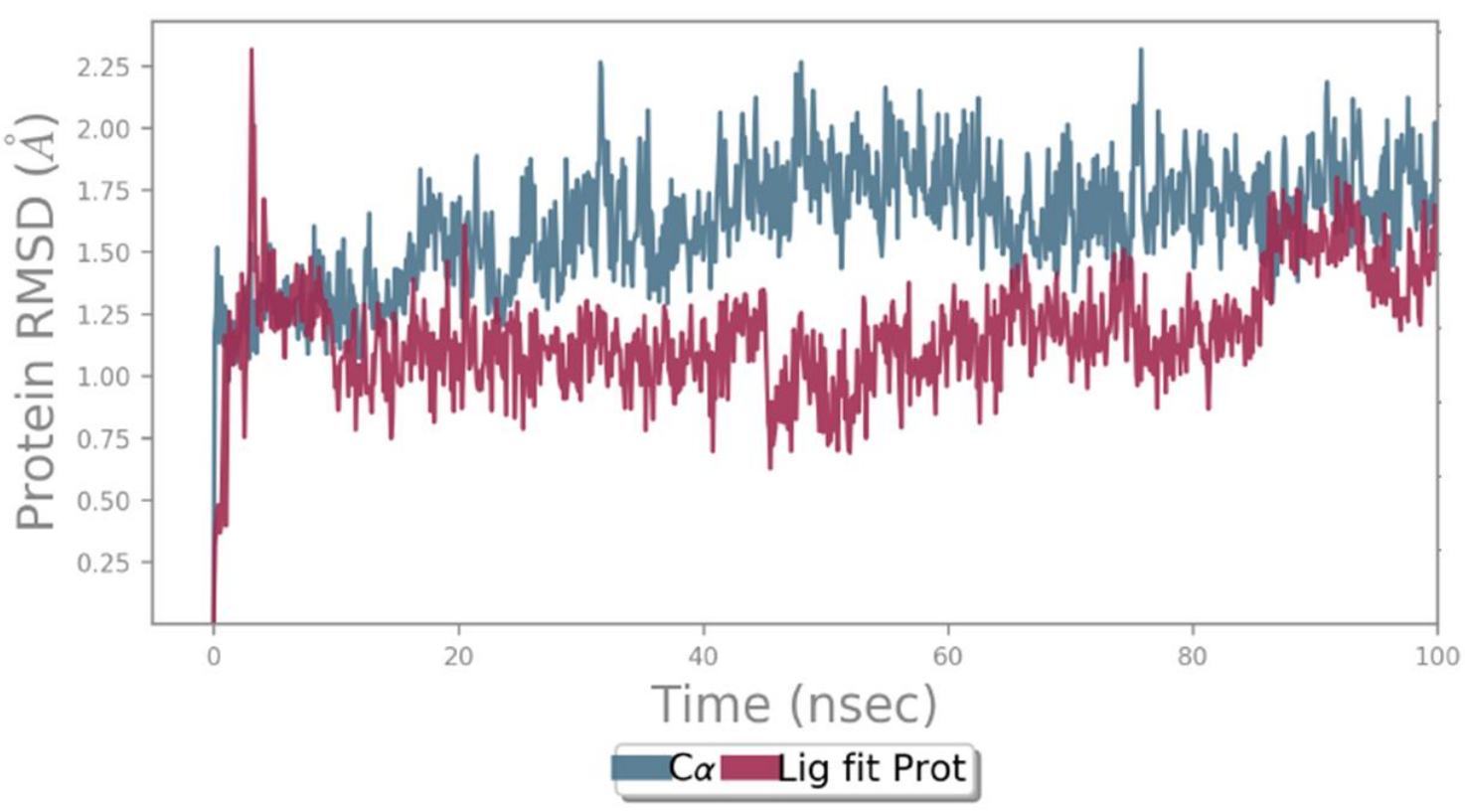

Fig. 2: Root Mean Square Deviation (RMSD) plot for interactive complex of 8Hydroxydihydrosanguinarine and $M$ protease during 0 - $100 \mathrm{~ns}$ of molecular dynamic simulation. 


\section{Ligand-Protein Contacts}

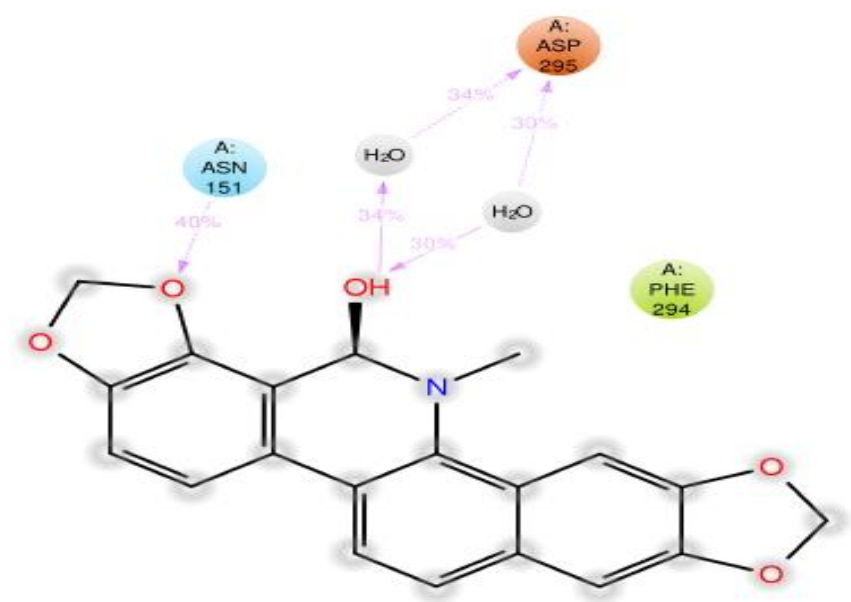

Charged (negative) Hydrophobic

Fig. 3: Illustration of bonds between Amino acid residues of $M$ protease and 8-

Hydroxydihydrosanguinarine during their interaction.

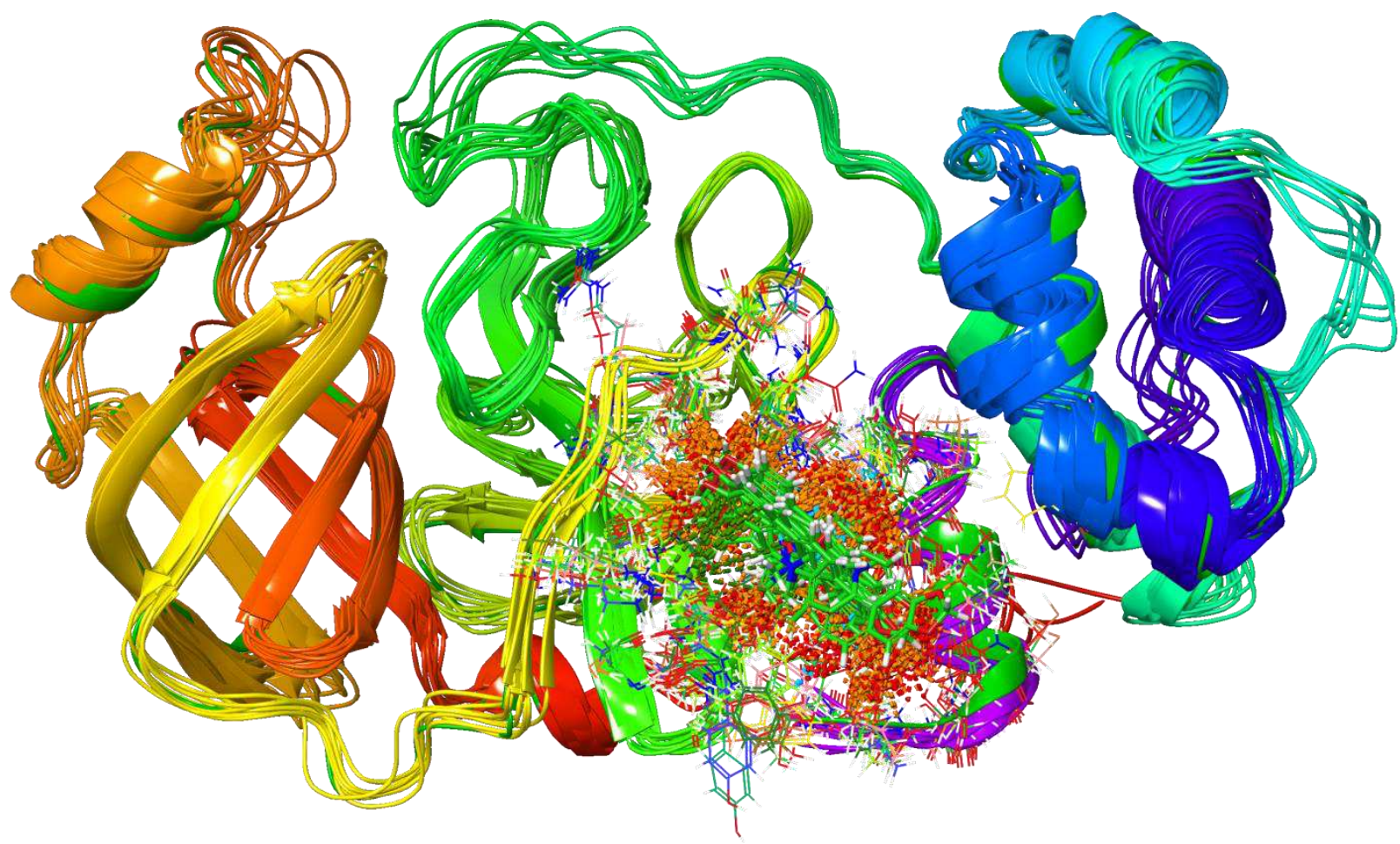

Fig. 4: Superimposition of multiple snapshots taken during M protease -8-HDS interaction derived from the $100 \mathrm{~ns}$ of $\mathrm{MD}$ simulations at $10 \mathrm{~ns}$ interval. 

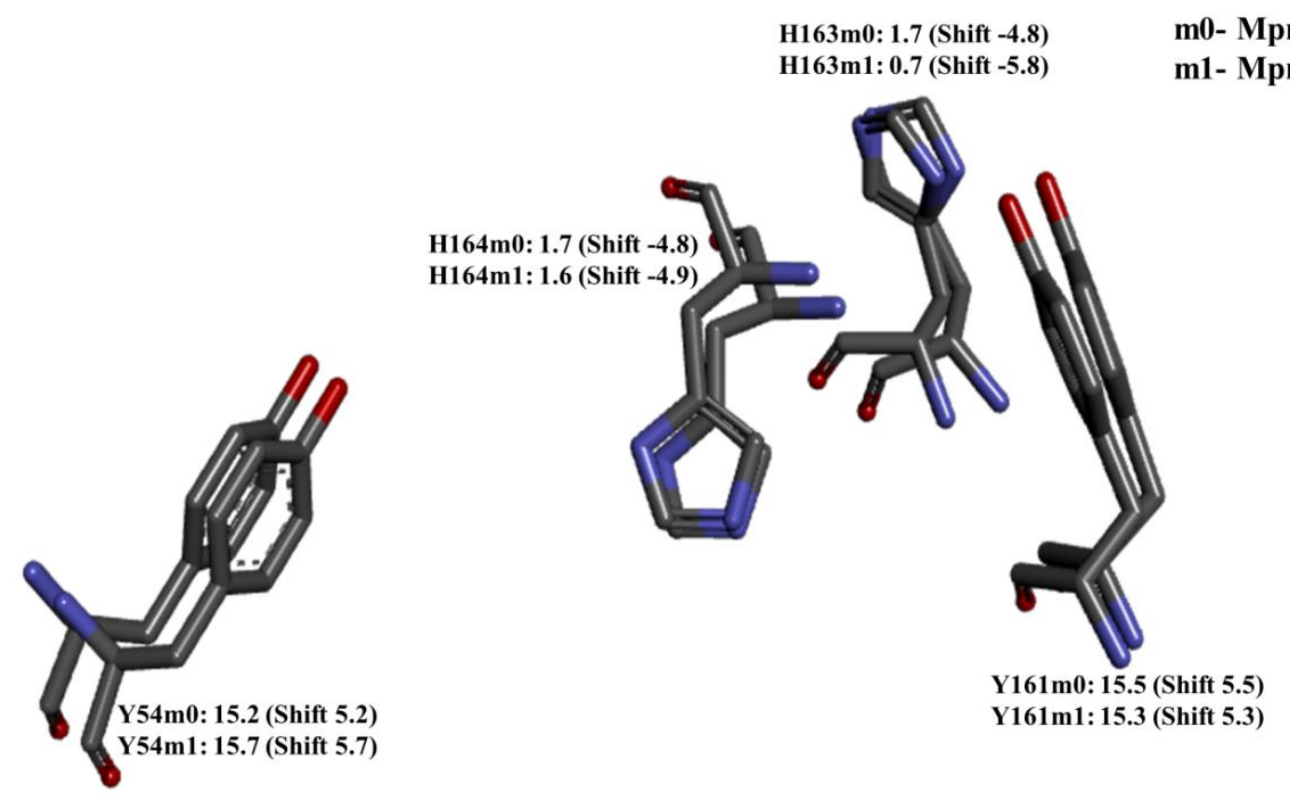

Fig. 5: Comparative study of $\mathrm{pK}_{\mathrm{a}}$ amino acid residues of $M$ pro in presence and absence of 8-HDS.

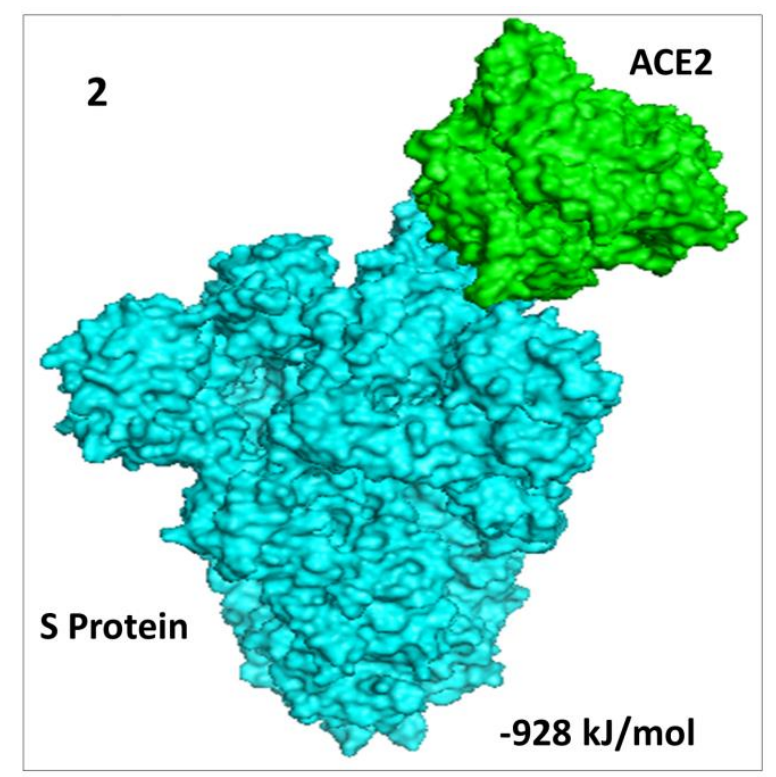

Fig. 6: Docked model depicting interaction of S-protein with ACE2 receptor in the absence of polyphenol. 


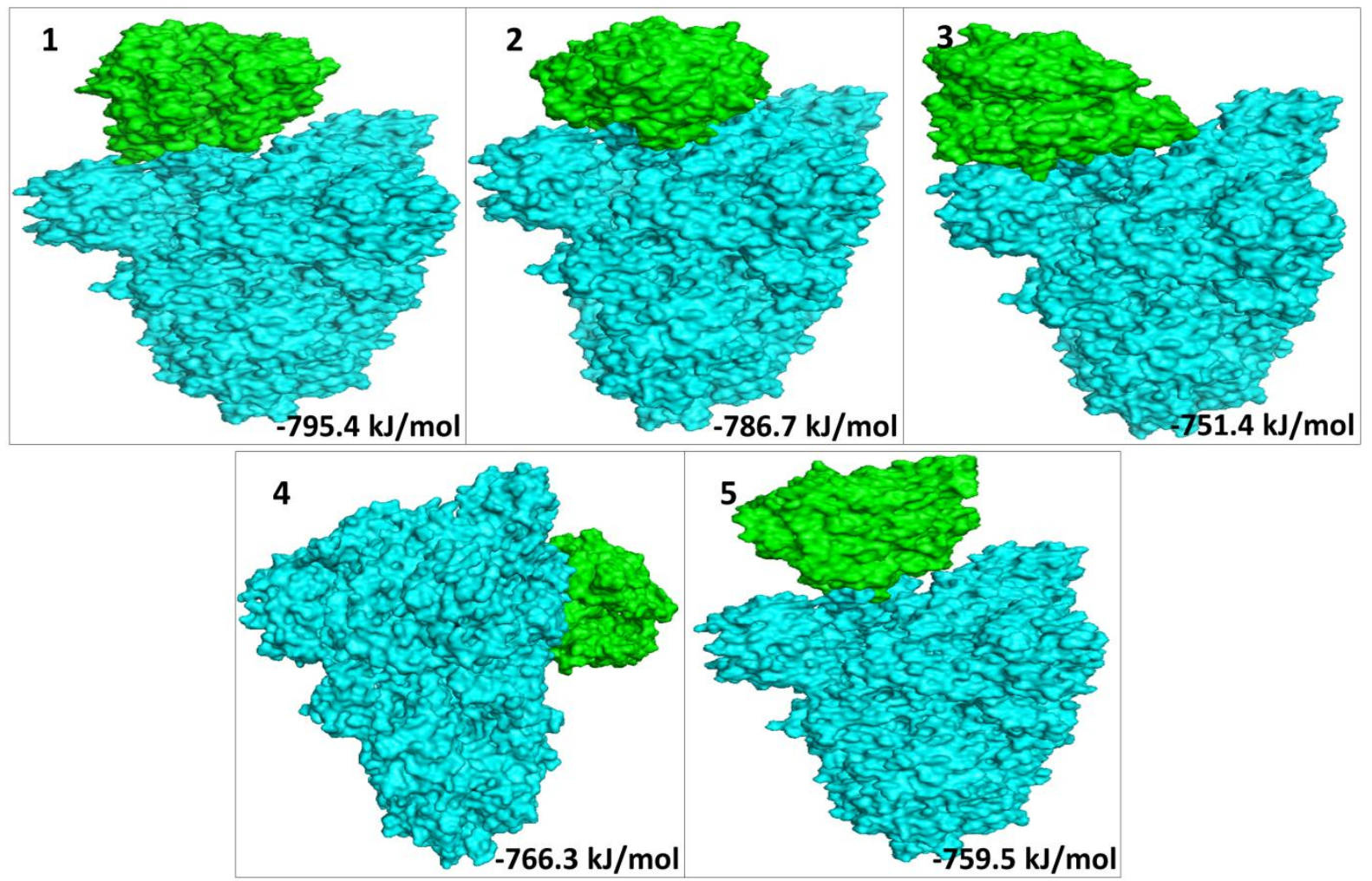

Fig. 7: The top 5 docked models displaying interaction of S-protein with ACE2 receptor in the presence of 8-HDS.

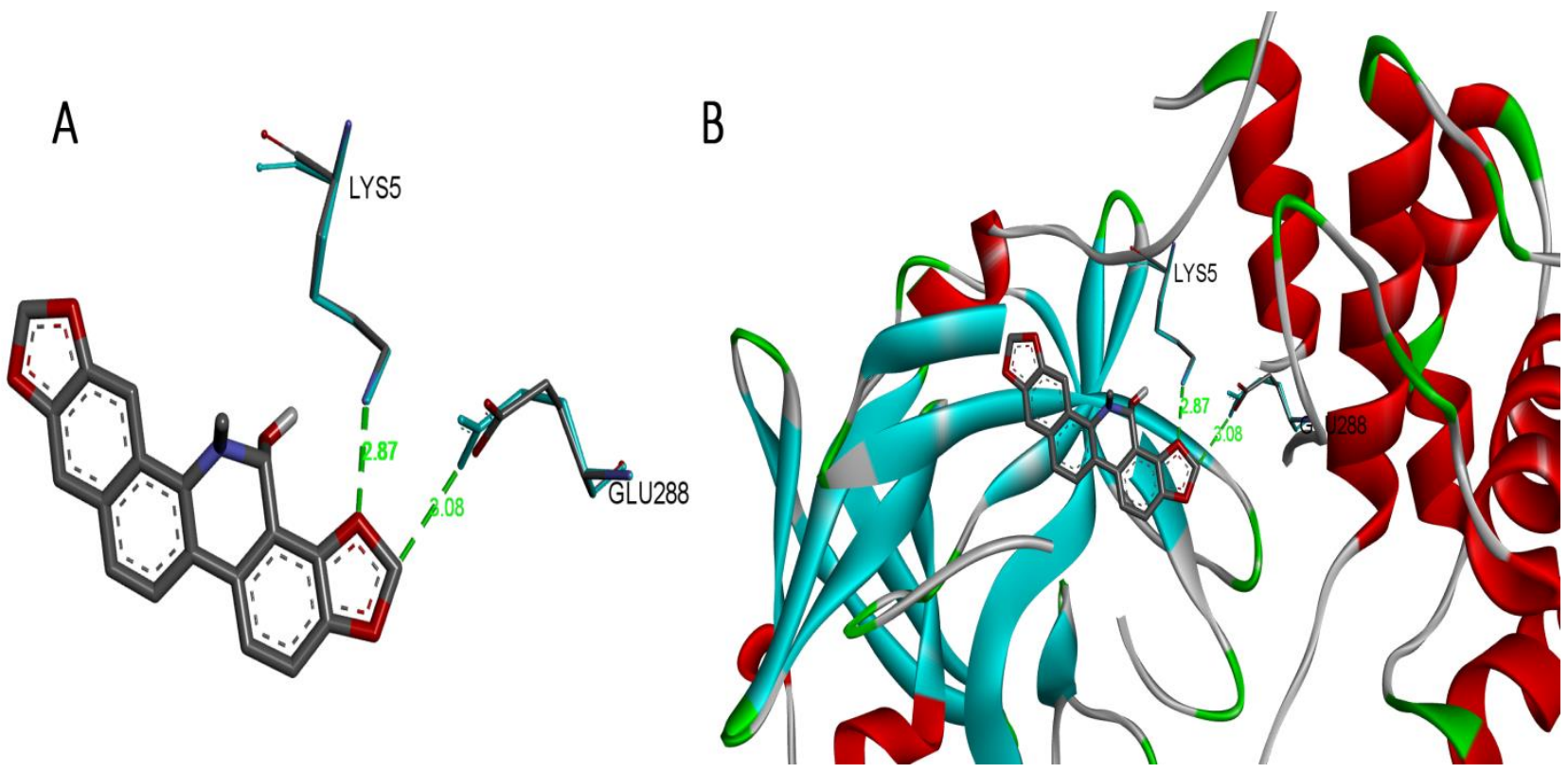

Fig. 8: Docked pose of 8-Hydroxydihydrosanguinarine in the binding pocket of $M$ protease. (A) Participating amino acids in the interaction of 8 Hydroxydihydrosanguinarine and M protease by Hydrogen bond, (B) Hydrogen 
bonds between 8 -Hydroxydihydrosanguinarine and $M$ proteasein Binding pocket.This Fig has been developed using Discovery Studio Visualizer (http://accelrys.com/products/ collaborative-science/biovia-discovery-studio/ visualization-download.php).
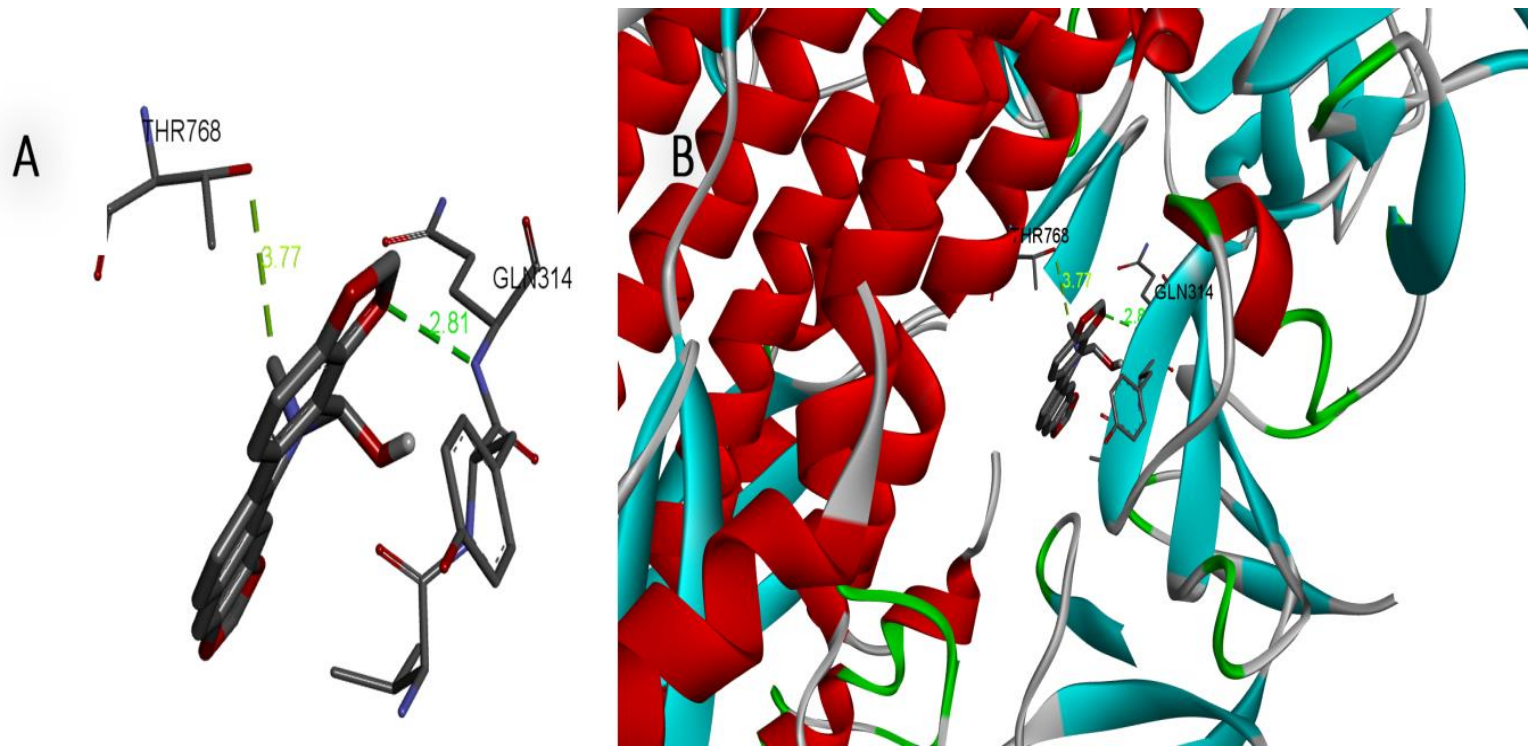

Fig. 9: Docked pose of 8-Hydroxydihydrosanguinarine in the binding pocket of $S$ Protein. (A) Participating amino acids in the interaction of 8 Hydroxydihydrosanguinarine and S Protein by Hydrogen bond, (B) Hydrogen bonds between 8 -Hydroxydihydrosanguinarine and S Protein in Binding pocket. This Fig has been developed using Discovery Studio Visualizer (http://accelrys.com/products/ collaborative - science/ biovia-discovery-studio/ visualization-download.php). 


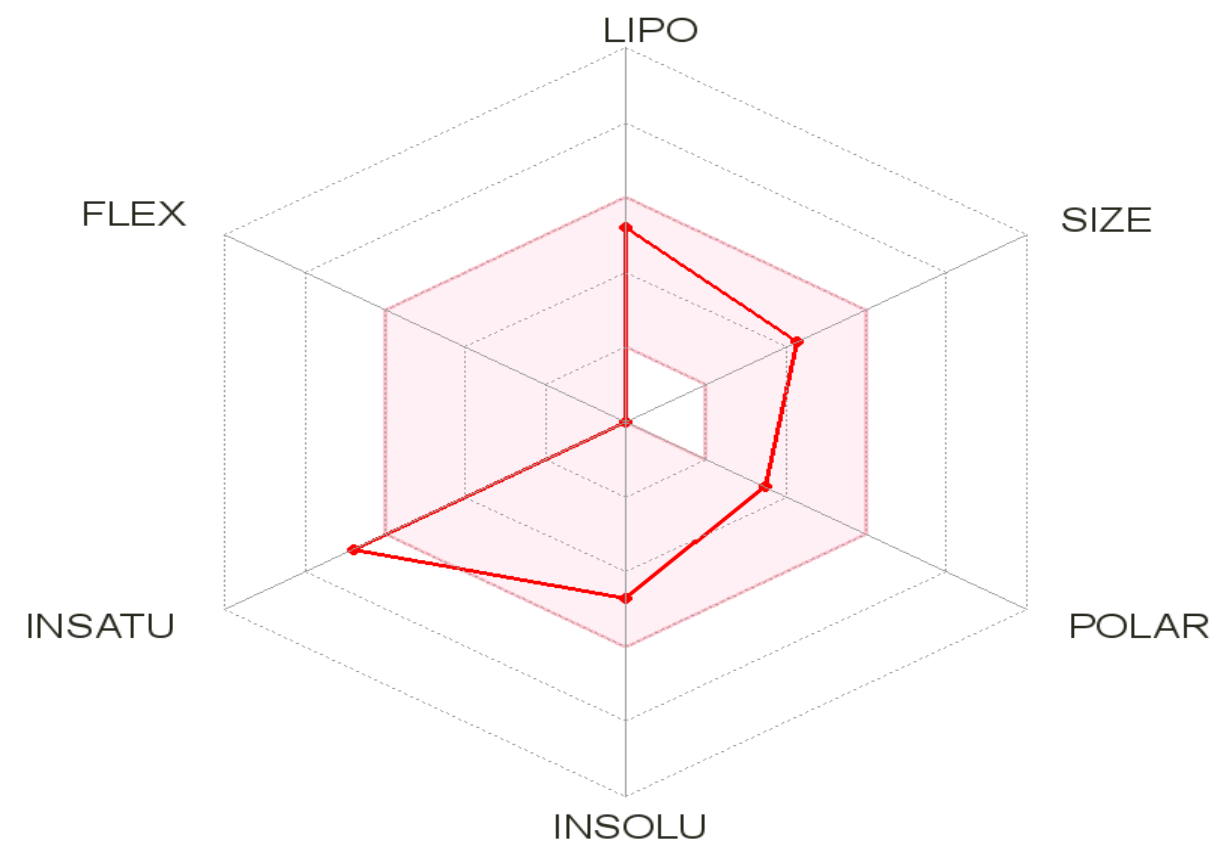

Fig. 10: The Bioavailability Radar depicts glimpse of the drug-likeness of a molecule. The pink area represents the optimal range for each properties of 8hydroxydihydrosanguinarine. 
Table-1: Protein-Protein interaction depicting 5 lowest binding energy for S ProteinACE2 complex in the presence or absence of 8-HDS.

\begin{tabular}{|cccc|}
\hline Macromolecule & Binding Positions & $\begin{array}{c}\text { Lowest Energy } \\
(\mathbf{k J} / \mathbf{m o l})\end{array}$ & $\begin{array}{c}\text { Average } \\
\text { Lowest Energy } \\
\text { (kJ/mol) }\end{array}$ \\
\hline S Protein- ACE2 & 1 & -923 & \\
\hline S Protein- ACE2 & 2 & -928.9 & \multirow{2}{*}{-901.2} \\
\hline S Protein- ACE2 & 3 & -902.4 & \\
\hline S Protein- ACE2 & 4 & -853.3 & \\
\hline S Protein with 8-HDS- ACE2 & 1 & -898.4 & \multirow{2}{*}{-771.86} \\
\hline S Protein with 8-HDS - ACE2 & 2 & -795.4 & \\
\hline S Protein with 8-HDS - ACE2 & 3 & -786.7 & \\
\hline S Protein with 8-HDS - ACE2 & 5 & -751.4 & -766.3 \\
\hline
\end{tabular}


Table - 2 : The binding energy, Interaction type and amino acid involved in interaction of S Protein and M protease of 2019-nCoV with 8hydroxydihydrosanguinarine.

\begin{tabular}{|c|c|c|c|c|}
\hline Protein- Ligand & Protein- Ligand 2D Interaction & $\begin{array}{l}\text { Binding } \\
\text { Affinity } \\
\text { (Kcal/mol) }\end{array}$ & Interaction & $\begin{array}{l}\text { AA: } \\
\text { Name; } \\
\text { AA: No }\end{array}$ \\
\hline \multirow{8}{*}{$\begin{array}{l}\text { M Protease-8- } \\
\text { hydroxydihydro } \\
\text { sanguinarine }\end{array}$} & \multirow{8}{*}{ 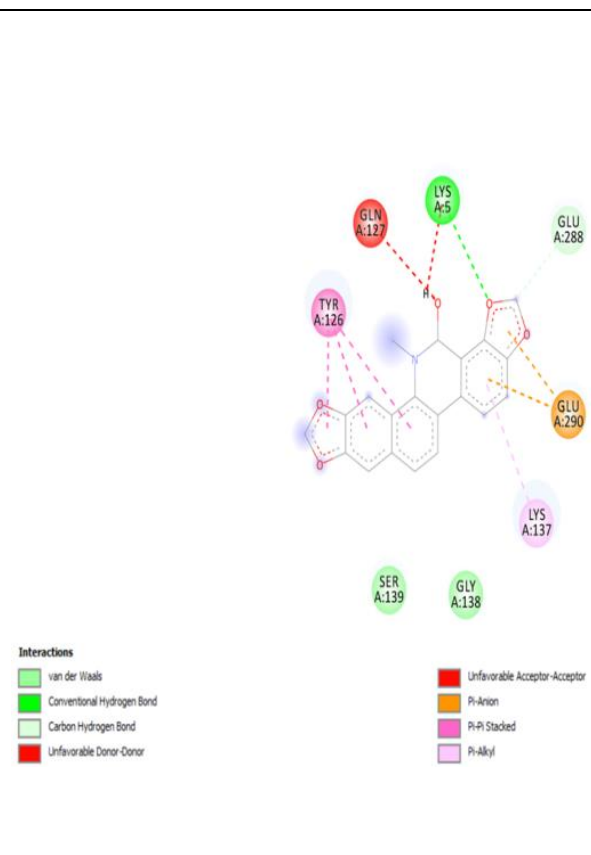 } & \multirow[t]{8}{*}{-10.3} & $\begin{array}{l}\text { Van der } \\
\text { Waal }\end{array}$ & $\begin{array}{l}\text { GLY138, } \\
\text { SER139 }\end{array}$ \\
\hline & & & $\begin{array}{l}\text { Carbon } \\
\text { Hydrogen } \\
\text { Bond } \\
\end{array}$ & GLU288 \\
\hline & & & $\begin{array}{l}\text { Conventional } \\
\text { Hydrogen } \\
\text { Bond } \\
\end{array}$ & LYS5 \\
\hline & & & $\begin{array}{l}\text { Unfavourable } \\
\text { Donor Donor }\end{array}$ & GLN127 \\
\hline & & & $\begin{array}{l}\text { Unfavourable } \\
\text { Acceptor } \\
\text { Acceptor }\end{array}$ & LYS5 \\
\hline & & & Pi- Anion & GLU290 \\
\hline & & & Pi-Pi Stacked & TYR126 \\
\hline & & & Pi-Alkyl & LYS137 \\
\hline \multirow[t]{7}{*}{$\begin{array}{l}\text { S Protein- 8- } \\
\text { hydroxydihydro } \\
\text { sanguinarine }\end{array}$} & \multirow{7}{*}{ 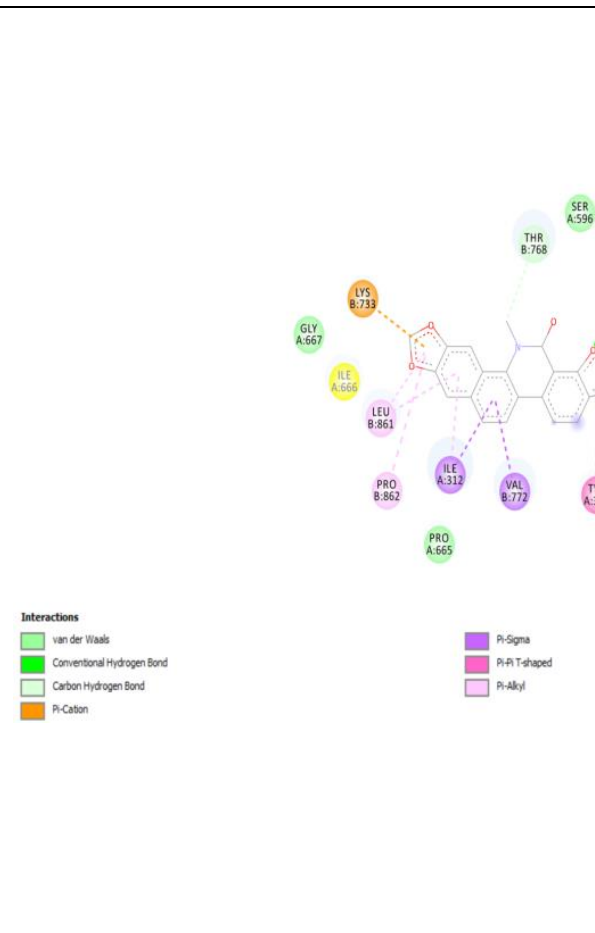 } & \multirow[t]{7}{*}{-9.4} & $\begin{array}{l}\text { Van der } \\
\text { Waal }\end{array}$ & $\begin{array}{l}\text { SER596, } \\
\text { PRO665, } \\
\text { ILE666, } \\
\text { GLY667, }\end{array}$ \\
\hline & & & $\begin{array}{l}\text { Carbon } \\
\text { Hydrogen } \\
\text { Bond } \\
\end{array}$ & THR768 \\
\hline & & & $\begin{array}{l}\text { Conventional } \\
\text { Hydrogen } \\
\text { Bond }\end{array}$ & GLN314 \\
\hline & & & Pi- Cation & LYS733 \\
\hline & & & Pi-Sigma & $\begin{array}{l}\text { ILE312, } \\
\text { VAL772 }\end{array}$ \\
\hline & & & $\begin{array}{l}\text { Pi-Pi T } \\
\text { Shaped }\end{array}$ & TYR313 \\
\hline & & & Pi Alkyl & $\begin{array}{l}\text { ILE312, } \\
\text { PRO862, } \\
\text { LEU 861 }\end{array}$ \\
\hline
\end{tabular}




\section{Figures}

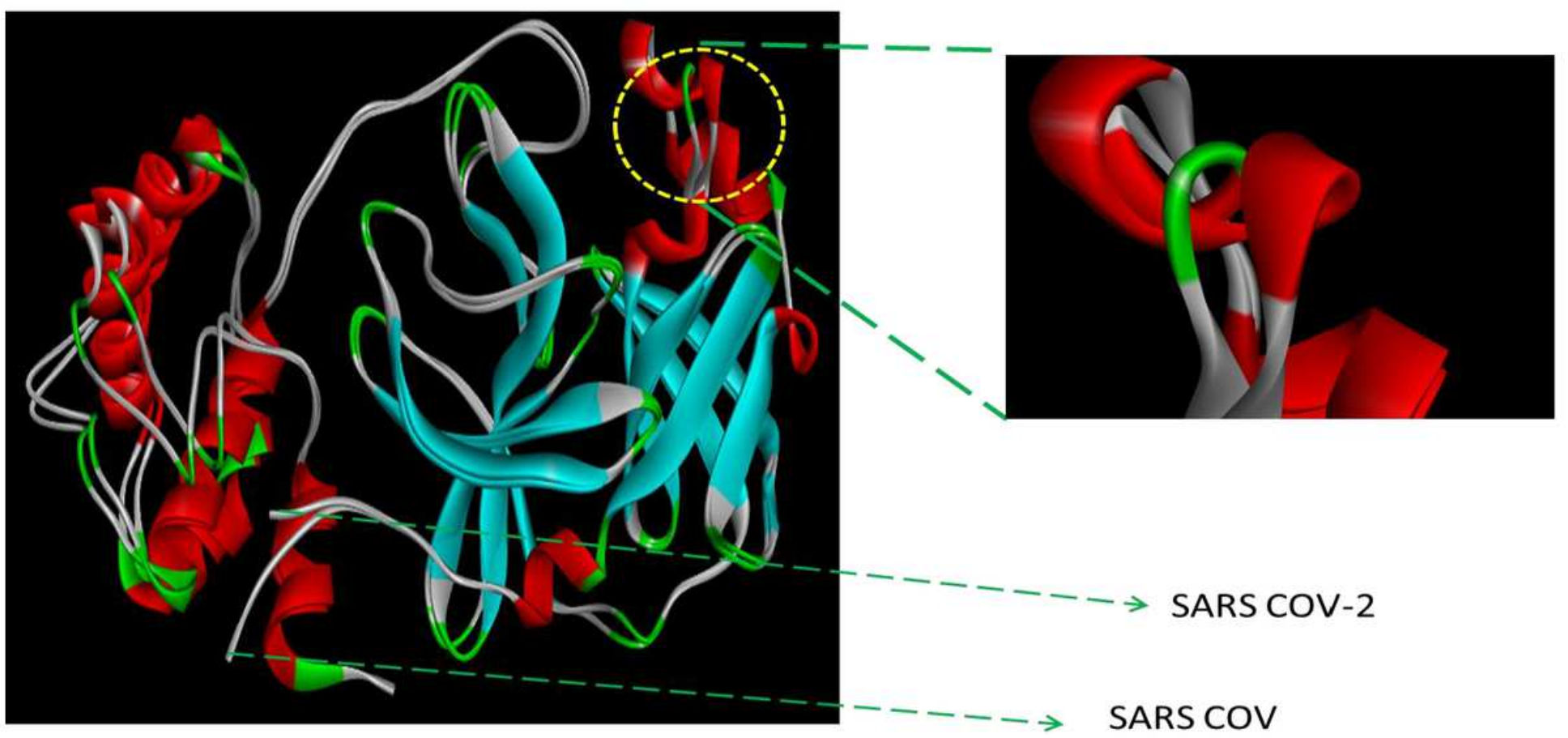

Figure 1

Structure- Structure alignment by superimposition of M protease of 2019-nCoV on SARS-CoV.

\section{Protein-Ligand RMSD}

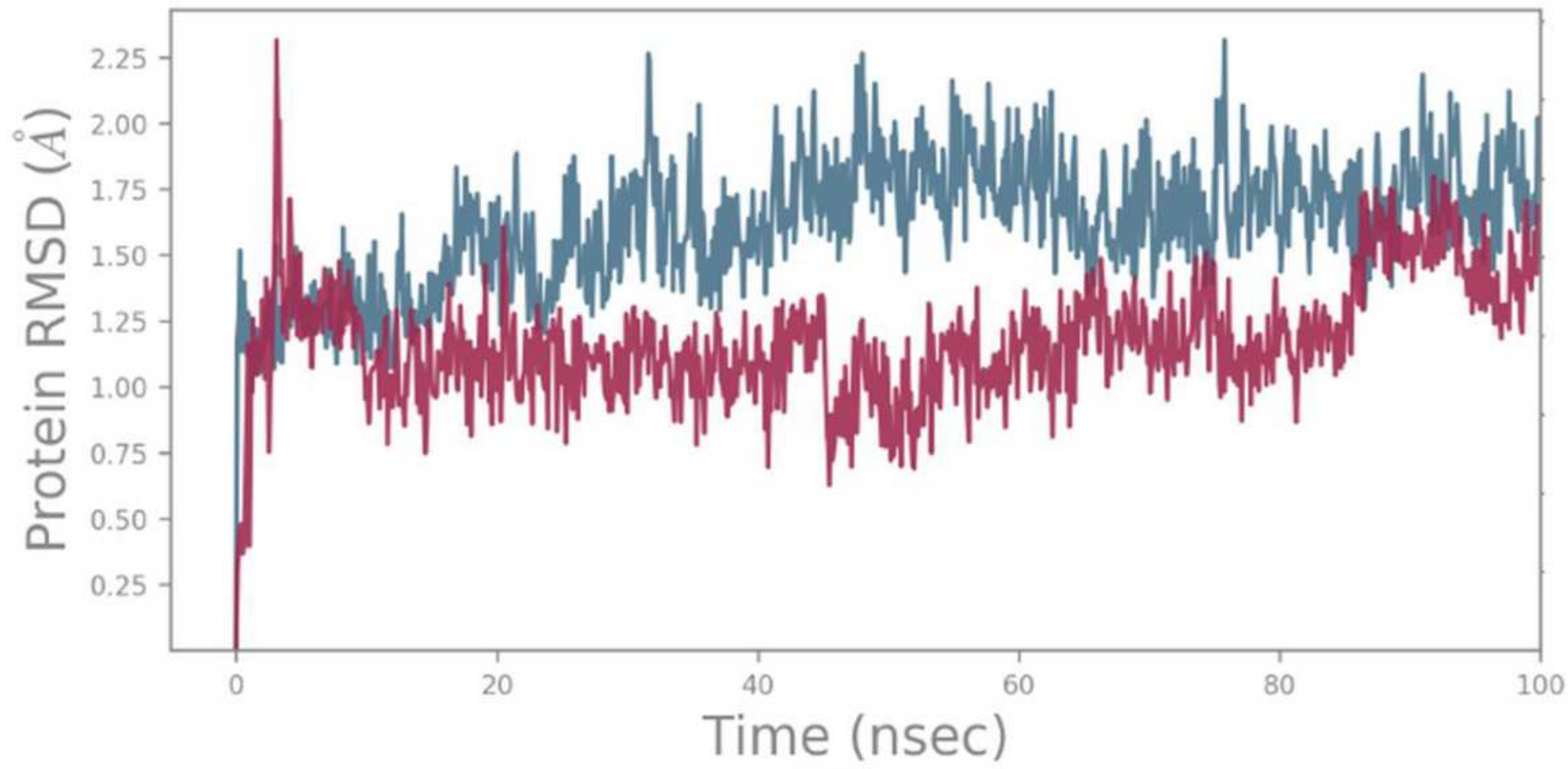

\section{$\mathrm{C} \alpha \square$ Lig fit Prot}


Figure 2

Root Mean Square Deviation (RMSD) plot for interactive complex of 8-Hydroxydihydrosanguinarine and M protease during $0-100$ ns of molecular dynamic simulation.

\section{Ligand-Protein Contacts}

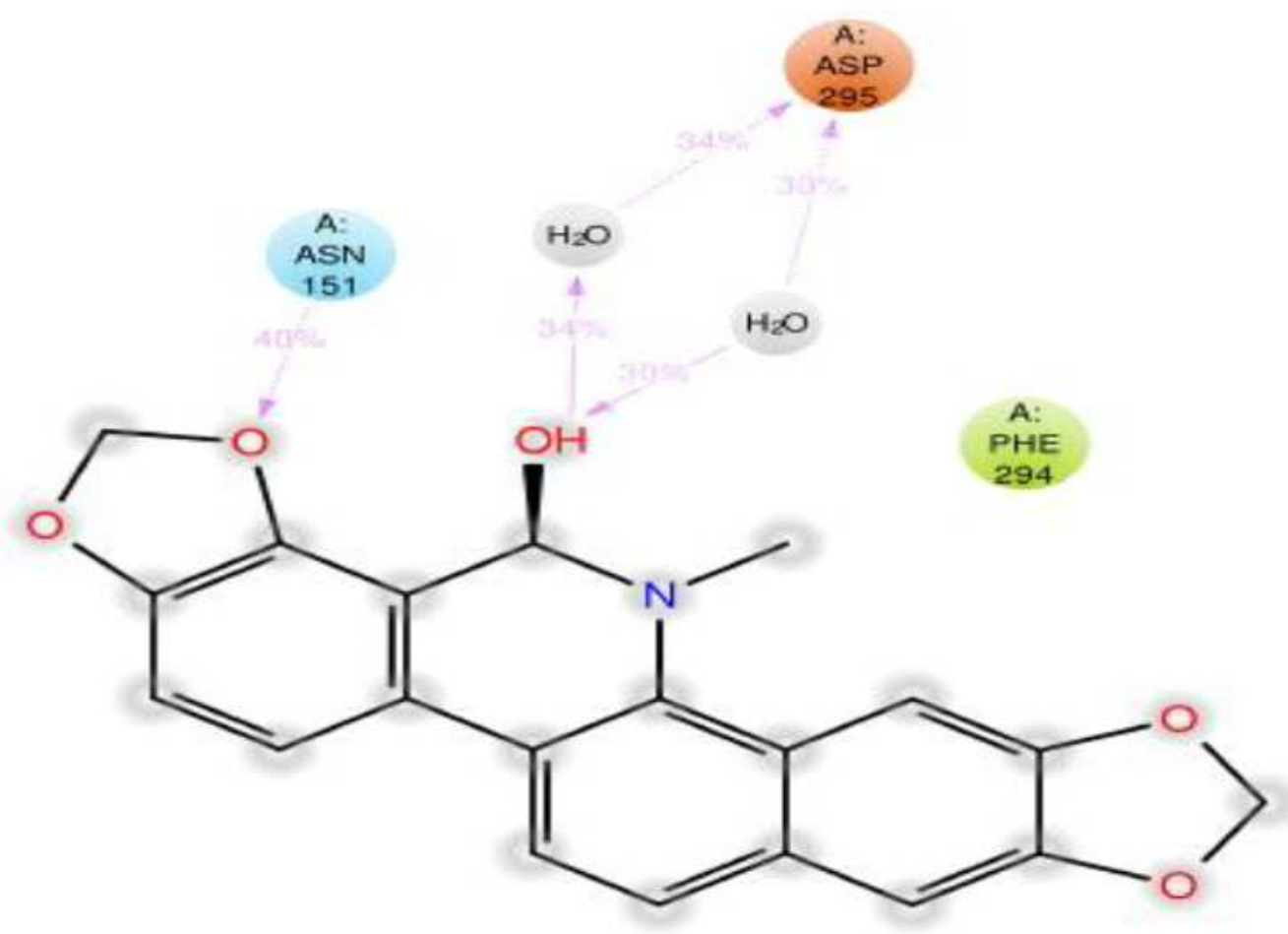

Charged (negative)

Hydrophobic
Polar

Water
Solvent exposure

\section{Figure 3}

Illustration of bonds between Amino acid residues of $\mathrm{M}$ protease and 8-Hydroxydihydrosanguinarine during their interaction. 


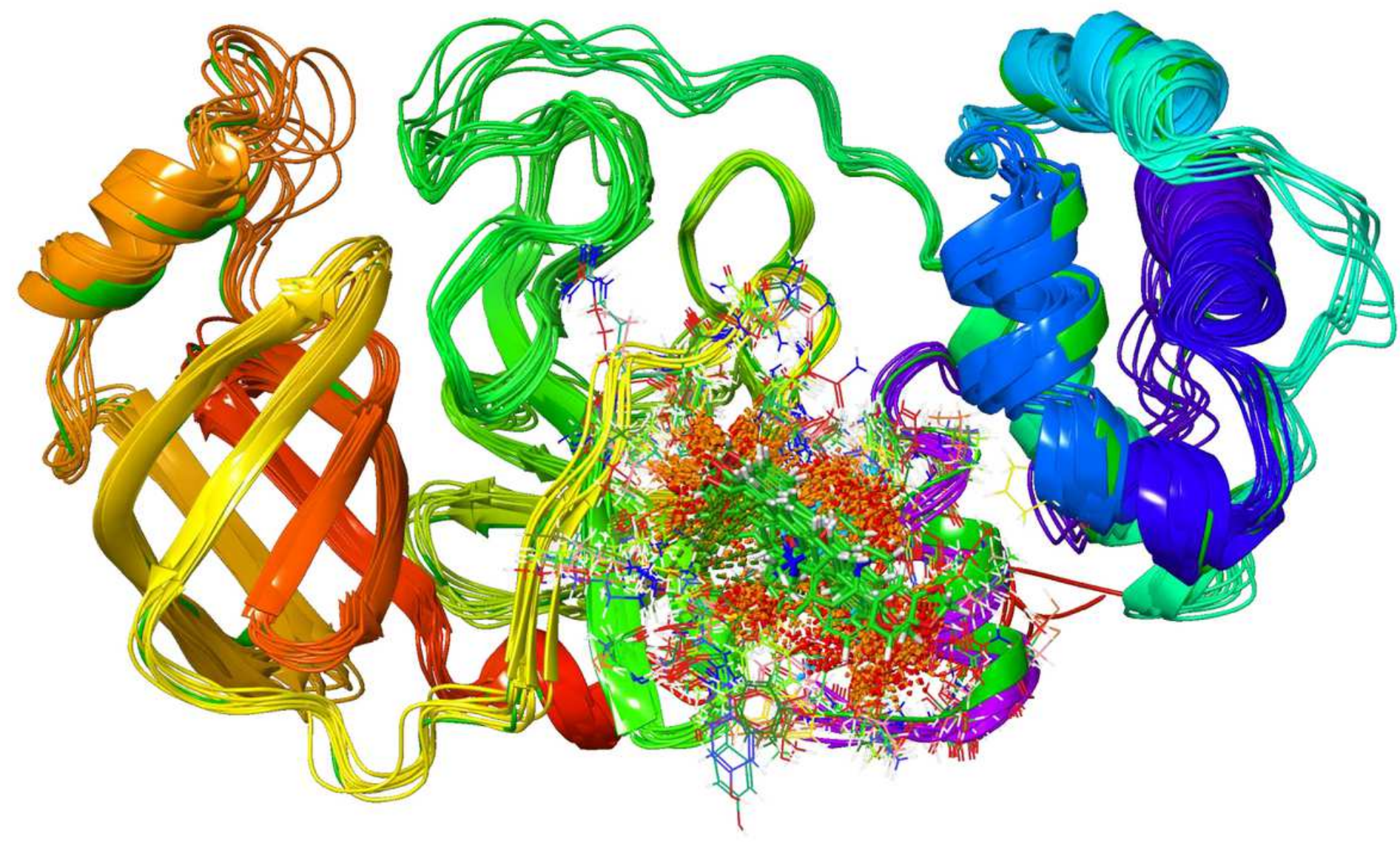

Figure 4

Superimposition of multiple snapshots taken during M protease -8-HDS interaction derived from the 100 ns of MD simulations at 10 ns interval.
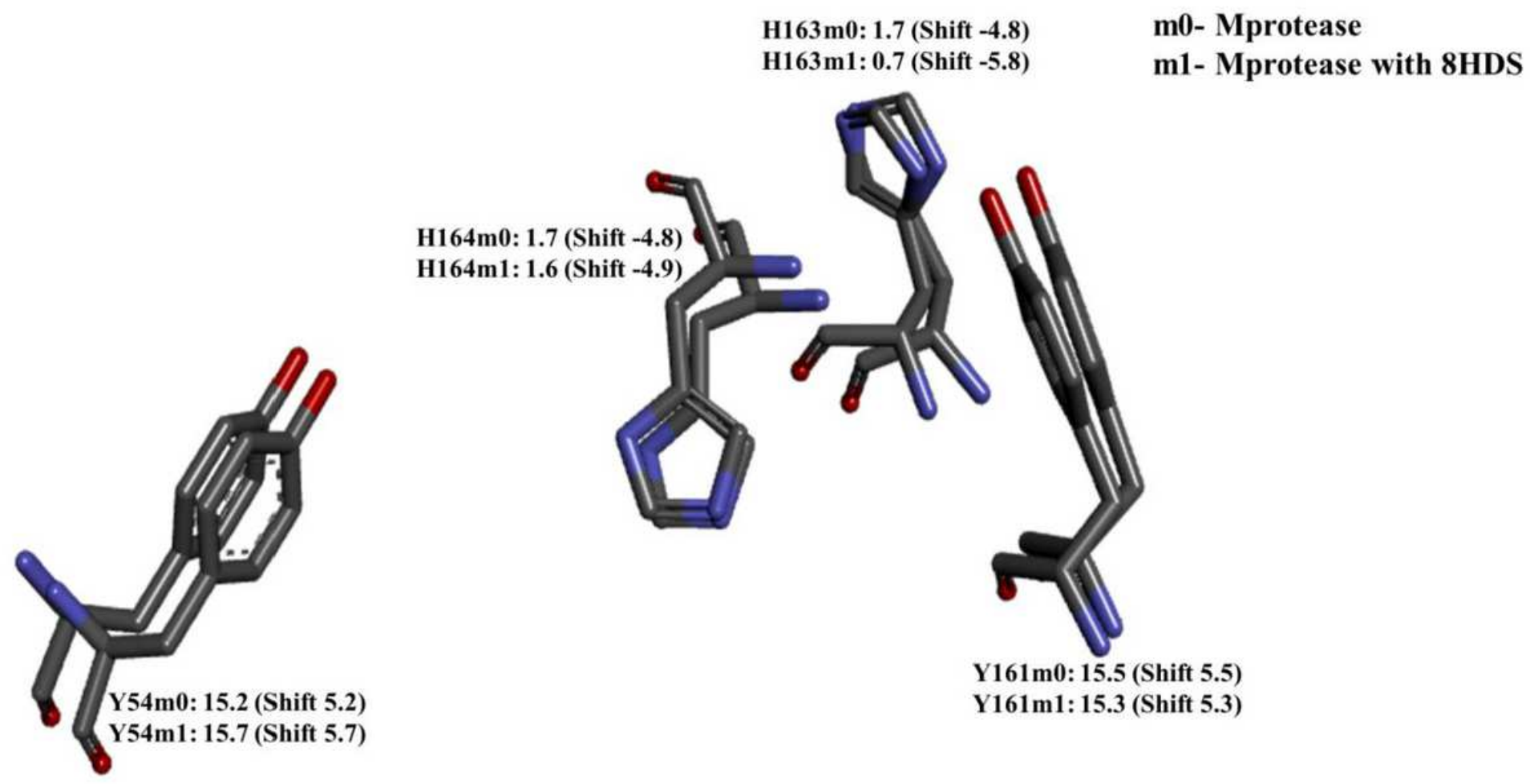
Figure 5

Comparative study of pKa amino acid residues of $\mathrm{M}$ pro in presence and absence of 8-HDS.

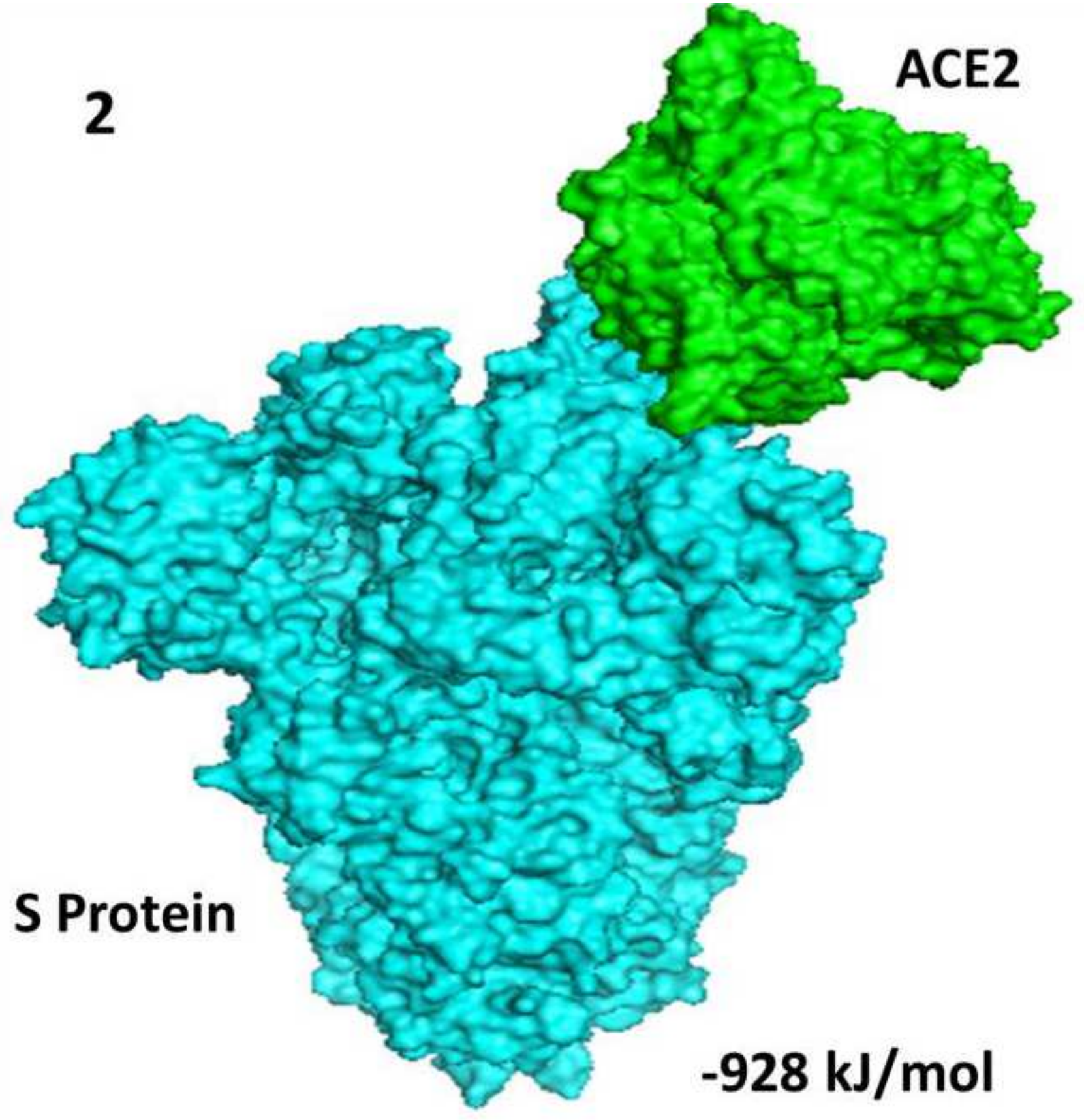

Figure 6

Docked model depicting interaction of S-protein with ACE2 receptor in the absence of polyphenol. 

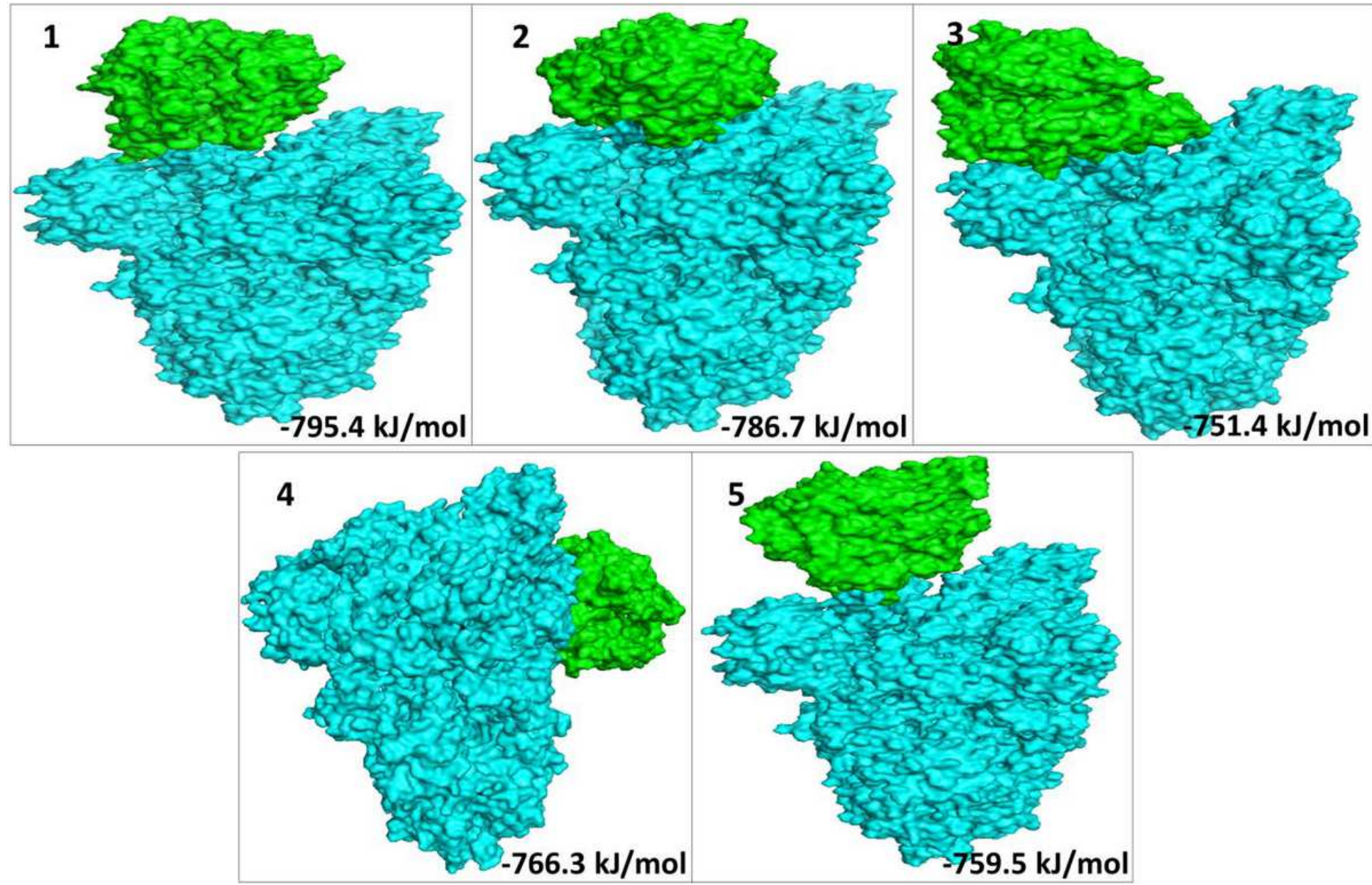

Figure 7

The top 5 docked models displaying interaction of S-protein with ACE2 receptor in the presence of 8-HDS.

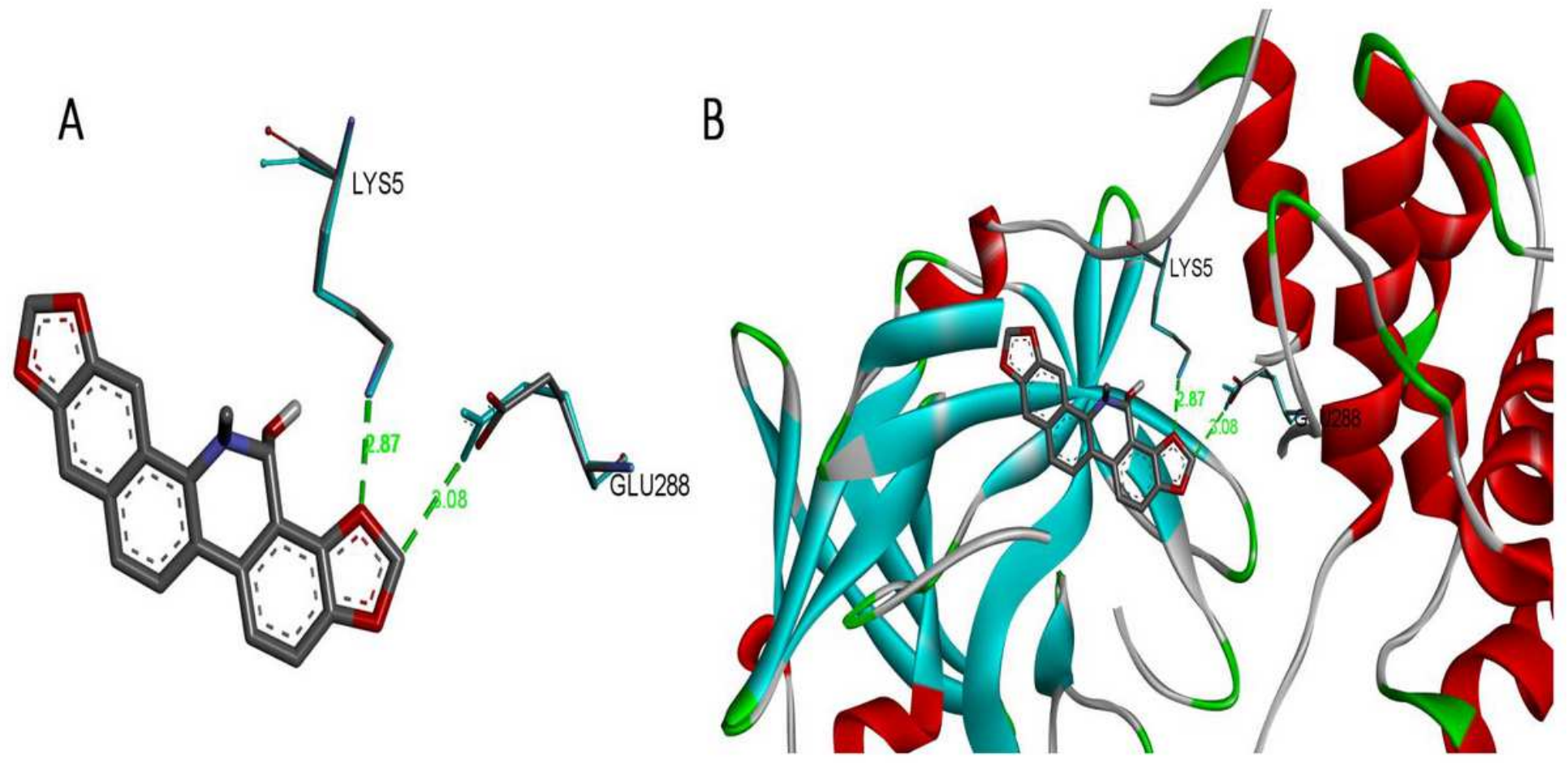




\section{Figure 8}

Docked pose of 8-Hydroxydihydrosanguinarine in the binding pocket of $\mathrm{M}$ protease. (A) Participating amino acids in the interaction of 8 -Hydroxydihydrosanguinarine and $\mathrm{M}$ protease by Hydrogen bond, (B) Hydrogen bonds between 8 -Hydroxydihydrosanguinarine and M proteasein Binding pocket.This Fig has been developed using Discovery Studio Visualizer (http://accelrys.com/products/ collaborativescience/biovia-discovery-studio/ visualization-download.php).
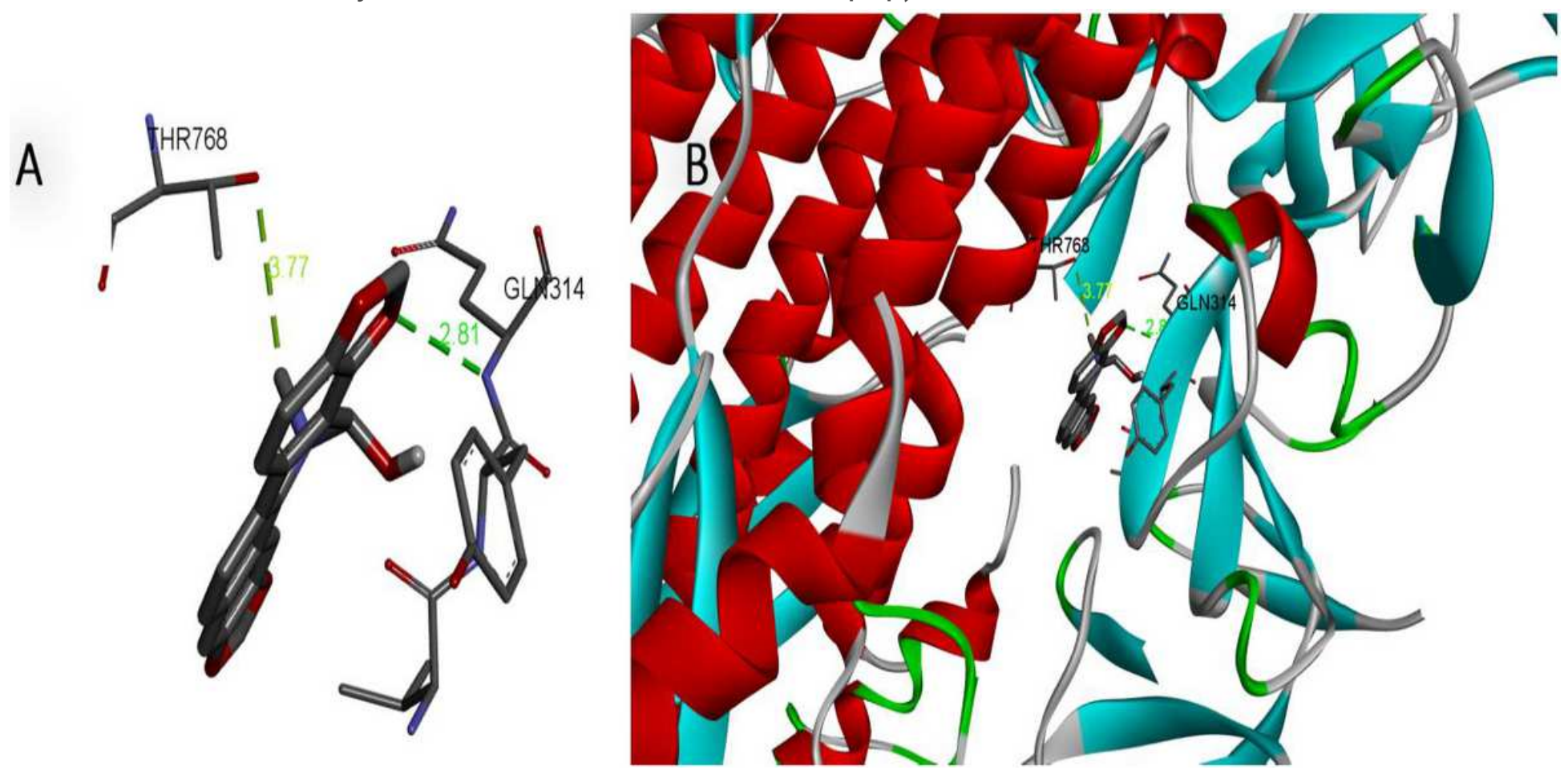

Figure 9

Docked pose of 8-Hydroxydihydrosanguinarine in the binding pocket of S Protein. (A) Participating amino acids in the interaction of 8 -Hydroxydihydrosanguinarine and S Protein by Hydrogen bond, (B) Hydrogen bonds between 8 -Hydroxydihydrosanguinarine and S Protein in Binding pocket. This Fig has been developed using Discovery Studio Visualizer (http://accelrys.com/products/ collaborative - science/ biovia-discovery-studio/ visualization-download.php). 


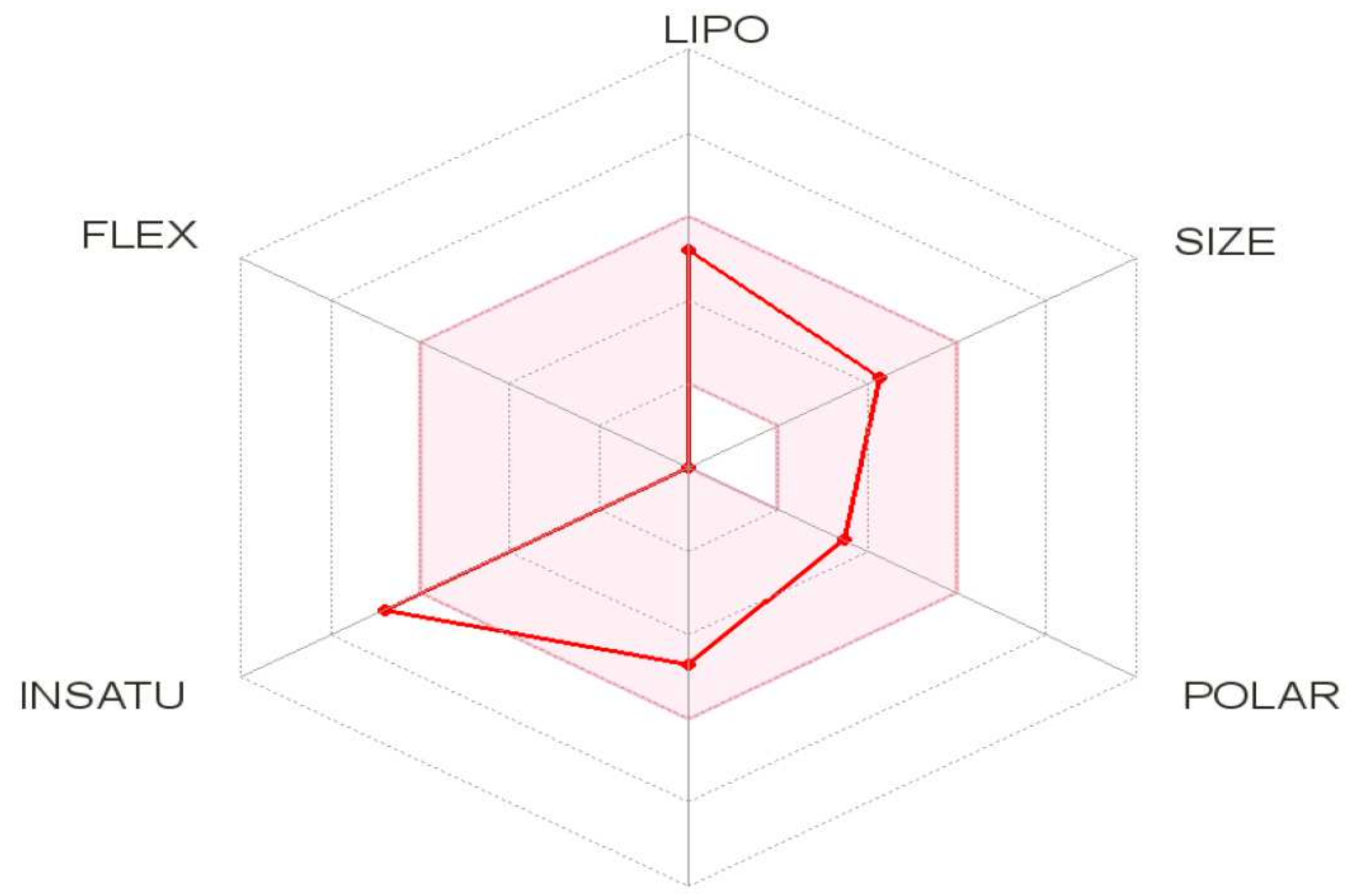

INSOLU

\section{Figure 10}

The Bioavailability Radar depicts glimpse of the drug-likeness of a molecule. The pink area represents the optimal range for each properties of 8-hydroxydihydrosanguinarine.

\section{Supplementary Files}

This is a list of supplementary files associated with this preprint. Click to download.

- Supportingdata8HDS.pdf

- GraphicalAbstract.jpeg 